\title{
GEOELECTRICAL IMAGES OF NORMAL FAULT ZONES: TECTONOPHYSICAL INTERPRETATION OF THE SHALLOW-DEPTH ELECTRICAL RESISTIVITY TOMOGRAPHY DATA ON THE BUGULDEIKA-CHERNORUD GRABEN IN THE WESTERN BAIKAL REGION
}

\author{
K. Zh. Seminsky ${ }^{1,2}$, A. A. Bobrov ${ }^{1}$ \\ ${ }^{1}$ Institute of the Earth's Crust, Siberian Branch of RAS, Irkutsk, Russia \\ ${ }^{2}$ Irkutsk Scientific Center, Siberian Branch of RAS, Irkutsk, Russia
}

\begin{abstract}
In the study of normal fault zones located in the central Baikal rift, a new approach was applied to process and interpret the shallow-depth electrical resistivity tomography data. This approach is based on the concepts of tectonophysics and considers three-stage formation of a fault and the corresponding three degrees of rock material disturbance, which are regularly detected in the rock mass. The degrees are established by statistical analysis of specific electrical resistance (SER) measured from the electrical resistivity tomography profile across the faults under study. Based on a geoelectrical profile, it is possible to identify the sites wherein the disturbed rocks show the indicators of the early, late and final stages of faulting. The profile provides the basis for specifying the boundaries of the fault zone and the main features of its internal structure. The tectonophysical approach was applied to study a series of normal fault zones varying in ranks. The zones are located on the sides of the Buguldeika-Chernorud graben located near the Olkhon Island in the Western Baikal region. By comparing the geoelectrical profiles constructed under the same methodology, it was established that the near-fault anomalies of electrical resistance are qualitatively similar. Their structure is defined by the general mechanism of normal faulting in the upper crust during sliding along a curved (listric) fault plane. The research results are consolidated in an idealized geoelectrical model: a 2D profile showing a low-resistance anomaly that corresponds to a normal fault zone. This anomaly is asymmetrical and mushroomshaped, and its internal structure is heterogeneous. In the lying wing of the fault, the anomaly reflects the fan-shaped set of secondary faults caused by the subvertical movements in the normal fault zone, which surface is steeply inclined to the horizon. In the hanging wing, the structure of the anomaly reflects a system of lens-like grabens that form above the surface of the main fault plane that becomes less inclined with depth. The structure of the geoelectrical model proposed for the Olkhon region follows the general regularities controlling formation of listric-shaped normal fault zones. This model can be widely used for diagnostics of tectonic settings and crustal extension structures in other regions.
\end{abstract}

Key words: strike-slip zone; fault; electrical resistivity tomography; geoelectrical profile; electrical conductivity anomaly; Baikal rift

For citation: Seminsky K.Zh., Bobrov A.A., 2018. Geoelectrical images of normal fault zones: tectonophysical interpretation of the shallowdepth electrical resistivity tomography data on the Buguldeika-Chernorud graben in the Western Baikal region. Geodynamics \& Tectonophysics 9 (4), 1339-1361. doi:10.5800/GT-2018-9-4-0399.

Для цитирования: Семинский К.Ж., Бобров А.А. Геоэлектрический имидж сбросовых зон: тектонофизическая интерпретация малоглубинной электротомографии на примере Бугульдейско-Чернорудского грабена в Западном Прибайкалье // Геодинамика и тектонофизика. 2018. Т. 9. № 4. С. 1339-1361. doi:10.5800/GT-2018-9-4-0399. 


\title{
ГЕОЭЛЕКТРИЧЕСКИЙ ИМИДЖ СБРОСОВЫХ ЗОН: ТЕКТОНОФИЗИЧЕСКАЯ ИНТЕРПРЕТАЦИЯ МАЛОГЛУБИННОЙ ЭЛЕКТРОТОМОГРАФИИ НА ПРИМЕРЕ БУГУЛЬДЕЙСКО-ЧЕРНОРУДСКОГО ГРАБЕНА В ЗАПАДНОМ ПРИБАЙКАЛЬЕ
}

\author{
К. Ж. Семинский ${ }^{1,2}$, А. А. Бобров 1 \\ ${ }^{1}$ Институт земной коры СО РАН, Иркутск, Россия \\ ${ }^{2}$ Иркутский научный центр СО РАН, Иркутск, Россия
}

\begin{abstract}
Аннотация: В статье представлены результаты применения нового подхода к обработке и интерпретации данных малоглубинной электротомографии на примере сбросовых зон центральной части Байкальского рифта. Подход основан на представлениях тектонофизики о трехстадийном формировании разлома, которое предопределяет закономерное существование в породном массиве трех уровней нарушенности субстрата. Уровни выявляются посредством статистического анализа величин удельного электрического сопротивления (УЭС), измеренных на профиле электротомографии, пересекающем изучаемый дизъюнктив. Это позволяет выделять на геоэлектрическом разрезе участки, у которых уровень нарушенности пород соответствует ранней, поздней и заключительной стадии разломообразования. Подобный разрез представляет основу для выделения границ разломной зоны и главных особенностей ее внутреннего строения. Тектонофизический подход был реализован для серии разноранговых сбросовых зон, располагающихся в бортах БугульдейскоЧернорудского грабена в Приольхонье. Сопоставление геоэлектрических разрезов, построенных в соответствии с единой методикой, позволило установить, что приразломные аномалии УЭС в качественном отношении подобны. Их строение определяется общим механизмом сбросообразования, реализующимся в верхней части коры при скольжении вдоль изогнутого (листрического) сместителя. Итогом исследования стала идеализированная геоэлектрическая модель, которая представляет двумерный разрез с низкоомной аномалией, соответствующей сбросовой зоне. Аномалия асимметрична, имеет грибоподобный вид и неоднородное внутреннее строение. Ее структура в лежачем крыле отражает веер вторичных разломов, образующихся при субвертикальных движениях в сбросовой зоне, которая у поверхности круто наклонена к горизонту. Строение аномалии в висячем крыле отражает систему линзоподобных грабенов, формирующихся над выполаживающейся с глубиной поверхностью главного сместителя. Предложенная на примере Приольхонья геоэлектрическая модель может иметь широкое применение для диагностики обстановок и структур растяжения земной коры, поскольку ее строение контролируется общими закономерностями формирования сбросовых зон, имеющих листрическую форму.
\end{abstract}

Ключевые слова: сбросовая зона; разлом; электротомография; геоэлектрический разрез; аномалия электропроводности; Байкальский рифт

\section{1. ВВЕДЕНИЕ}

Традиционное понимание разломов подразумевает выделение в их строении подзоны вторичных разрывов и повышенной трещиноватости ("damage zone"), которая обрамляет узкую подзону тектонитов главного сместителя (“core zone"). В связи с тем, что разломные зоны контролируют важные в практическом отношении сопутствующие процессы (сейсмичность, миграция флюидов и газов), внимание к изучению их структуры и напряженного состояния не ослабевает [Chester et al., 1993; Caine et al., 1996; Faulkner et al., 2010; Jeanne et al., 2012; Bense et al., 2013; Schueller et al., 2013; Seminsky, 2014, 2015; Choi et al., 2016]. Углубление исследований в данной области приводит к выделению но- вых особенностей строения разломных зон [Jones, Knipe, 1996; Clausen et al., 2003; Berg, Skar, 2005; Mitchell, Faulkner, 2009; Seminsky, 2014, 2015; Choi et $a l ., 2016]$. В настоящее время представляется целесообразным выделять дополнительный - третий элемент в структуре разломных крыльев, который назван периферийной подзоной распространения парагенетически связанных трещин [Seminsky, 2015].

Как видно из рис. 1 , трехчленное строение разломной зоны (рис. $1, a, 6$ ) определяется существованием трех главных стадий ее формирования, которые были выделены на основе тектонофизического анализа процесса разломообразования (рис. 1, в) [Seminsky, 2015; Seminsky et al., 2016]. Так, для разлома с полной историей развития по мере удаления 


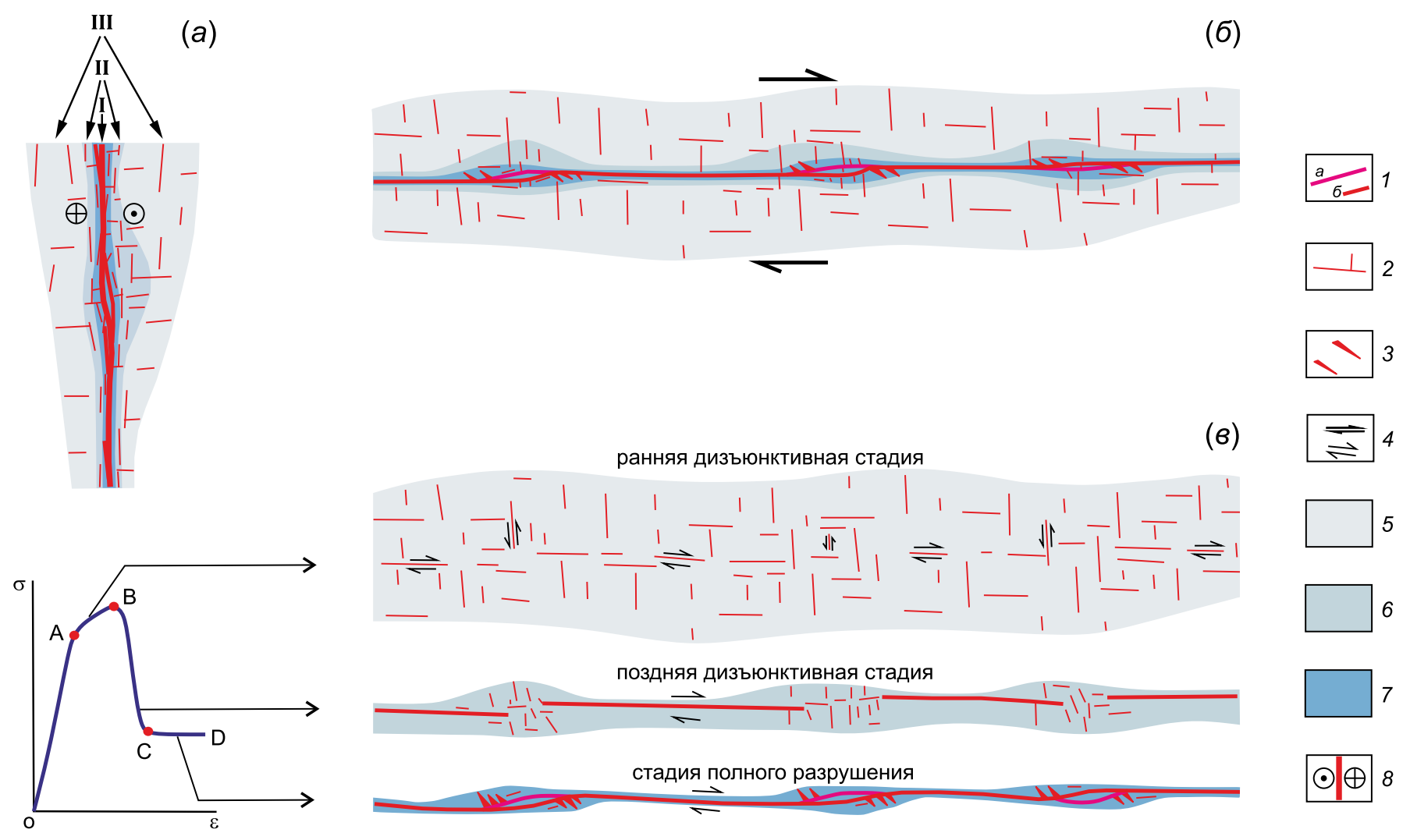

Рис. 1. Тектонофизическая модель зонального строения разломной зоны (на примере правого сдвига).

(a) - поперечная зональность строения разломной зоны как следствие стадийности ее развития: I - подзона главного сместителя 1-го порядка, II - подзона разрывов 2-го порядка и повышенной трещиноватости, III - периферийная подзона парагенетически связанных трещин. (б) - внутренняя структура зоны полностью сформировавшегося разлома. (в) - схемы активных разрывов на трех стадиях разломообразования, каждой из которых соответствует характерный отрезок кривой нагрузка ( $\sigma)$ - дефор-

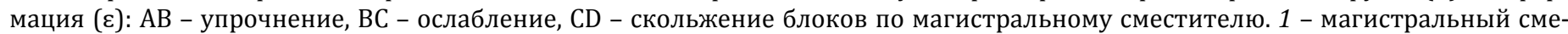
ститель (а) и разрывы 2-го порядка (б); 2 - трещины скола; 3 - трещины отрыва; 4 - характер смещения крыльев по разломной зоне в целом и составляющим ее разрывам; 5 - границы разломной зоны на ранней дизъюнктивной стадии; 6 - то же на поздней дизъюнктивной стадии; 7 - то же на стадии полного разрушения; 8 - направление скольжения крыла сдвига: на наблюдателя (слева) и от наблюдателя (справа).

Fig. 1. Tectonophysical model showing the zonal structure of a fault zone (in case of a right-lateral normal fault).

(a) - transverse zoning of the fault zone as a result of its staged development: I - subzone of the main fault plane of the 1st order, II - subzone of the $2^{\text {nd }}$-order fractures and increased fracturing, III - peripheral subzone of paragenetically related fractures. (6) - internal structure of the completely formed fault zone. $(\theta)$ - schemes of active fractures at three stages of faulting (each stage corresponds to a characteristic segment of the load $(\sigma)$ /deformation $(\varepsilon)$ curve): AB - strengthening, BC - weakening, CD - slip of the blocks along the main fault plane. 1 - main fault plane (a) and the $2^{\text {nd }}$-order fractures (б); 2 - cleavage cracks; 3 - tensile cracks; 4 - displacements of the wings along the fault zone as a whole and along the fractures comprising the fault zone; boundaries of the fault zone: 5 - early stage of faulting; 6 - late stage; 7 - complete destruction; 8 - slip direction of the normal fault wing: towards the observer (left) and from the observer (right).

от подзоны главного (магистрального) сместителя (I), образовавшегося на заключительной стадии полного разрушения, выделяется подзона разрывов 2-го порядка и повышенной трещиноватости (II), формирующаяся на поздней дизъюнктивной стадии, а также периферийная подзона парагенетически связанных трещин (III), имевшая место на ранней дизъюнктивной стадии разломообразования.

В пределах территорий с широким распространением рыхлых отложений картирование разломных зон представляет известную трудность и осу- ществляется с применением малоглубинных геофизических методов. Среди них в последние годы активно используется электротомография - современная разновидность вертикальных электрических зондирований. В комплексе с радоновой съемкой или георадиолокацией электротомография позволяет достоверно выделять разломы в районах распространения слабосцементированных отложений [Demanet et al., 2001; Negri, Leucci, 2006; Vanneste et al., 2008; Štěpančíková et al., 2010; Thinova et al., 2011; Fischer et al., 2012; Putiška et al., 2012; Schütze et al., 2012; Zarroca et al., 2012; Galli et al., 


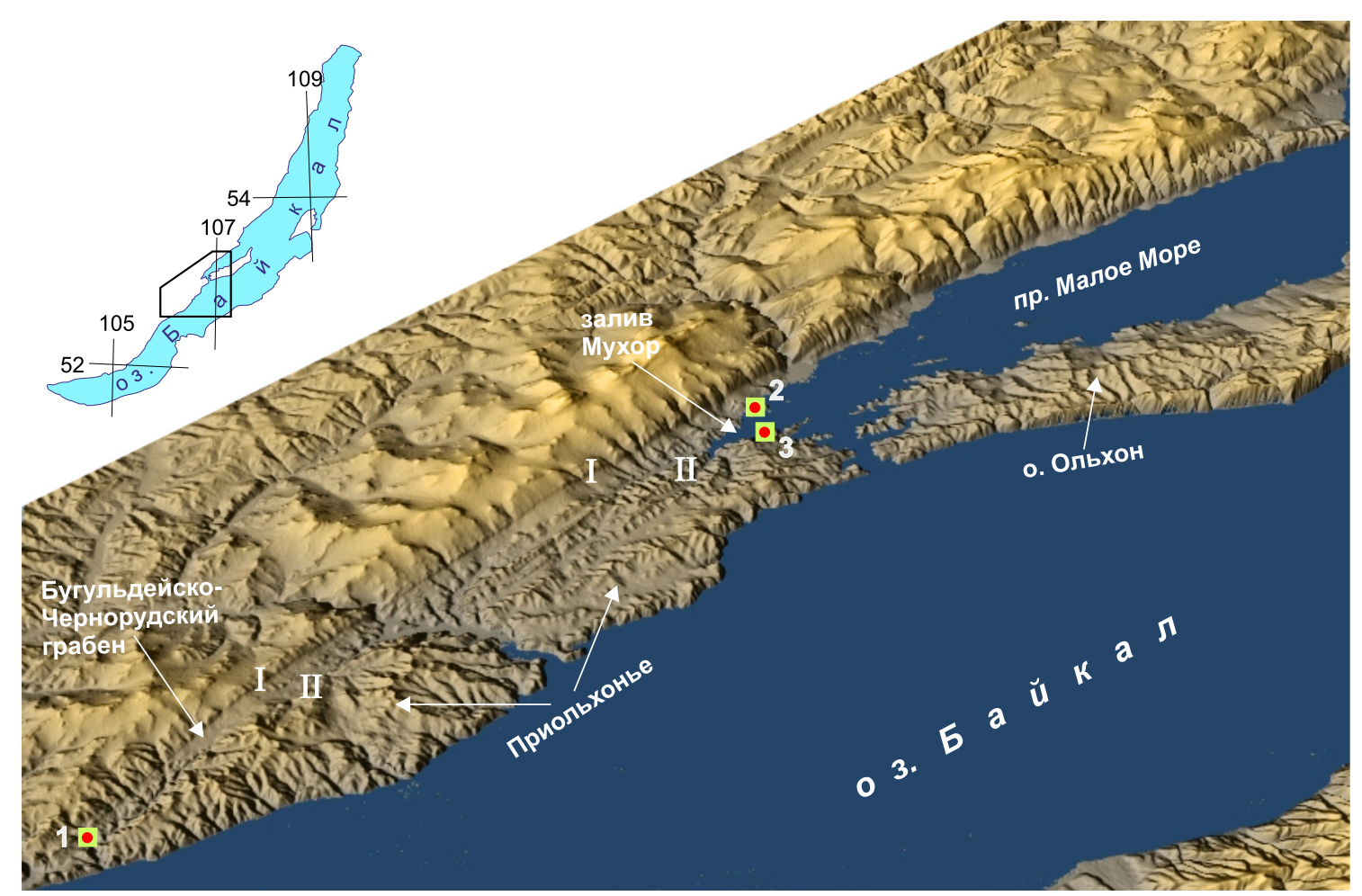

Рис. 2. Обзорная схема расположения разломов и участков проведения электротомографических исследований в Приольхонье (Западное Прибайкалье). Цифры на схеме: I - Приморский сброс; II - Тырган-Кучелгинский сброс; 1-3 - площади исследований (1 - Бугульдейская, 2 - Улирбинская, 3 - Онтхойская).

Fig. 2. Locations of the faults and the electrical resistivity tomography study areas in the Olkhon region (Western Baikal region). Numbers: I - Primorsky normal fault; II - Tyrgan-Kuchelga normal fault; 1-3 - studied areas (1 - Buguldeika, 2 Ulirba, 3 - Ontkhoi).

2014; Drahor, Berge, 2017; Bhat et al., 2018]. Более того, тектонофизический подход к интерпретации получаемых в поле материалов электротомографии дает возможность картировать внешние границы зоны разлома, а также участки, для которых степень и характер нарушенности соответствуют подзонам I и II [Seminsky et al., 2016]. Повышение эффективности данного метода связано с приобретением опыта его практического применения для разломов с разным внутренним строением, специфика которого в первую очередь определяется характером перемещения крыльев.

Целью данной статьи было представить результаты использования тектонофизического подхода к интерпретации данных электротомографии, проведенной для того, чтобы установить характер проявления в поле удельного электрического сопротивления (УЭС, $\rho$ ) сбросовых разломных зон, формирующихся в условиях растяжения земной коры.

Опорным полигоном для проведения исследований являлось Приольхонье в Западном Прибайкалье (рис. 2), территория которого в тектоническом отношении относится к области краевых под- нятий Саяно-Байкальского складчатого пояса. Развитые в регионе полихронные метаморфические комплексы представлены мраморами, биотитовыми гнейсами, гранитогнейсами и пегматитами, которые почти повсеместно характеризуются субвертикальным залеганием с простиранием в северовосточном направлении.

Согласно исследованиям предшественников [Sherman, 1977; Pavlov, 1979; Pleshanov, Romazina, 1981; Kukley, 1985; Sherman et al., 1992, 1994; Mats, 1993; Levi et al., 1997; Fedorovsky, 1997; Delvaux et al., 1995, 1997; Mats et al., 2001; Logachev, 2003; Sklyarov, 2005; Seminsky et al., 2013; и дp.], породы претерпели несколько этапов интенсивных деформаций, среди которых в рамках фанерозоя выделяют раннепалеозойское сжатие, раннекайнозойский сдвиг и позднекайнозойское растяжение земной коры. Как следствие, скальные массивы Прибайкалья характеризуются интенсивной нарушенностью, что проявляется в наличии плотной сети трещин и разломов, подвижки по которым на последнем этапе тектогенеза - при формировании Байкальского рифта - способствуют растяжению коры в направлении СЗ-ЮВ. 
Наиболее крупные рифтовые впадины заполнены водами оз. Байкал и в полной мере недоступны для изучения наземными методами. Одним из немногих исключений является юго-западная сухопутная часть Маломорской впадины (рис. 2), которая локализуется в Приольхонье и представлена Бугульдейско-Чернорудским грабеном [Mats et al., 2001]. С северо-запада и юго-востока он ограничен Приморским и Тырганским региональными сбросами, внутреннее строение которых представлено локальными разломами 2-го, 3-го и более высоких порядков, характеризующимися аналогичным типом смещения. Представители этих разноранговых сбросов, наряду с Приморским региональным разломом, стали объектами электротомографии, реализованной для достижения поставленной цели в профильном варианте.

Задачи исследования состояли в следующем:

1) провести в Приольхонье электротомографические измерения по профилям, пересекающим разноранговые сбросовые зоны, отчетливо выраженные в структурных признаках, рельефе и/или поле эманаций радона;

2) применить для каждого из профилей тектонофизический подход к обработке данных электротомографии, построить геоэлектрические разрезы и выделить в их пределах границы сбросовых зон, а также главные особенности внутреннего строения;

3) провести сравнительный анализ характера проявления разноранговых сбросовых зон в поле УЭС и предложить их двумерную геоэлектрическую модель, определяющуюся главными чертами разломной структуры.

\section{2. ПЛОЩАДИ И МЕТОДЫ ИССЛЕДОВАНИЙ}

Площади исследований - Бугульдейская (1), Улирбинская (2) и Онтхойская (3) (рис. 2) - представляли массивы горных пород, нарушенные сбросами, которые относятся к региональному, локальному или мелкому локальному рангу. На каждой из площадей зоны влияния и главные сместители изученных дизъюнктивов были отчетливо проявлены в геолого-структурных, геоморфологических и/или эманационных признаках. Это позволило изучить геоэлектрические разрезы разноранговых сбросов посредством создания профилей, полностью пересекающих зоны их динамического влияния.

На Бугульдейской площади профиль электротомографии длиной 1800 м пересек зону Приморского разлома (рис. $3, a$ ), который принадлежит к региональному рангу, так как протягивается на первые сотни километров в качестве бортового сброса для Бугульдейско-Чернорудского и северо-восточнее - Маломорского грабена (см. рис. 2). Сместитель Приморского сброса проявлен уступом в рельефе (рис. 3,2$)$, а зона его влияния - в виде широкой (>500 м) приразломной аномалии на профиле радоновой съемки (рис. $3, \partial$ ), обработка которого была проведена в соответствии с ранее разработанной методикой [Seminsky, Demberel, 2013; Seminsky et al., 2014].

На Улирбинской площади (см. рис. 2) первым объектом исследования был одноименный разлом, который относится к локальному рангу, поскольку на протяжении нескольких десятков километров формирует береговую линию залива Мухор. Зона его влияния, вследствие высокой нарушенности пород, выражена широким (>200 м) понижением в рельефе, пересеченным профилем электротомографии длиной 700 м (рис. 4, $a, 2$ ). Вторым и третьим объектами исследования на данной площади были мелкие локальные разломы, входящие в зону главного сместителя Улирбинского сброса (рис. 5, a). Она была пересечена профилем электротомографии, протяженность которого (110 м) на 40 м превышала ширину приразломной аномалии почвенного радона (см. рис. $4, \partial$ ).

Объекты исследования на Онтхойской площади (см. рис. 2) по структурной позиции аналогичны локальному разлому и мелким локальным сбросам Улирбинской площади, но, в отличие от них, принадлежат к юго-восточному борту БугульдейскоЧернорудского грабена. Мелкий локальный сброс принадлежит к зоне главного сместителя Онтхойского разлома, который относится к локальному рангу. Этот небольшой разлом был ранее детально изучен комплексом геолого-структурных, геоморфологических, эманационных методов [Seminsky et al., 2008, 2013; Cheremnykh, 2010; Seminsky, Bobrov, 2012; Seminsky, 2015], так как использовался в качестве эталонного объекта для отработки тектонофизического подхода к интерпретации материалов малоглубинной электротомографии [Seminsky et al, 2016]. Созданный в ходе этих работ геоэлектрический разрез будет в данной статье привлечен к обсуждению результатов, полученных по новым объектам сбросового типа, включая локальный Онтхойский сброс (рис. 6, ж). Для его изучения был пройден профиль электротомографии длиной 460 м (рис. 6, 6, e), а также проведены дополнительные геолого-структурные исследования (рис. 6, a, в).

Комплекс методов, реализованных на перечисленных выше площадях, состоял из электротомографии, а также геолого-структурных, геоморфологических и/или эманационных наблюдений и измерений, используемых для выявления внешних границ зоны и особенностей их внутреннего строения. 
(a)

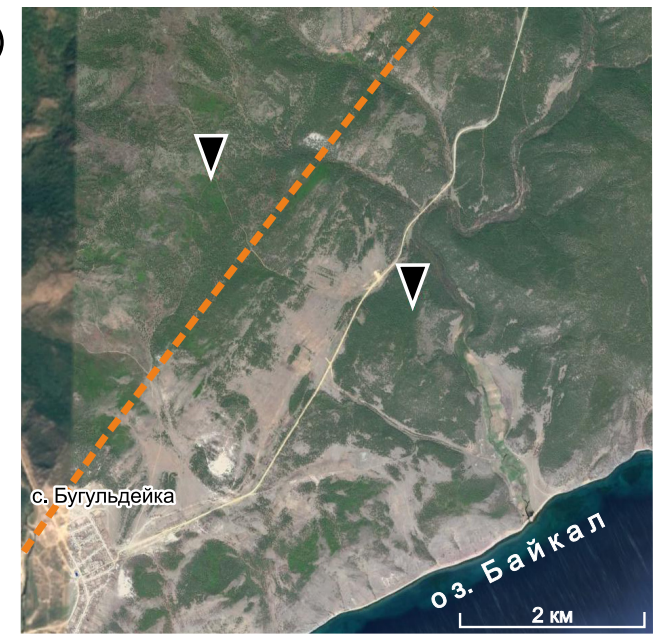

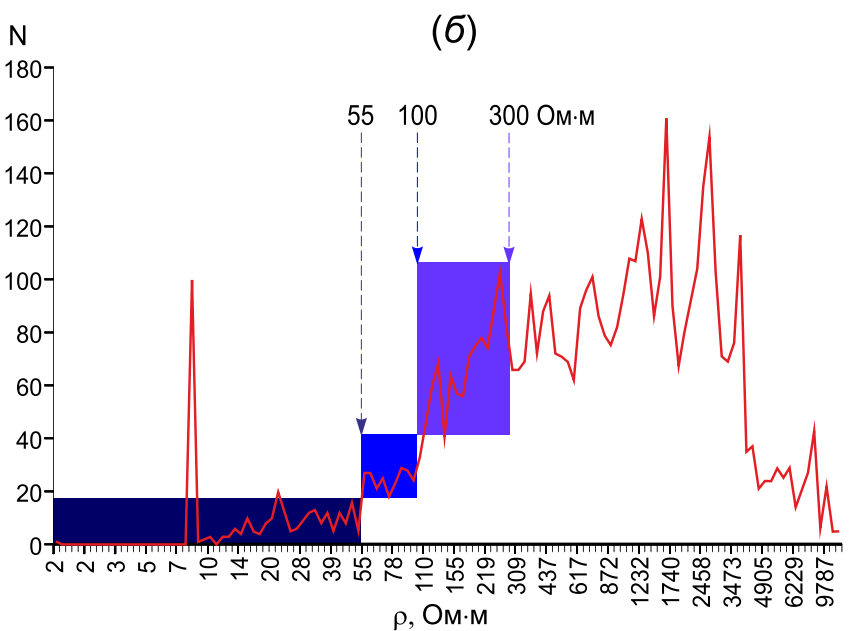

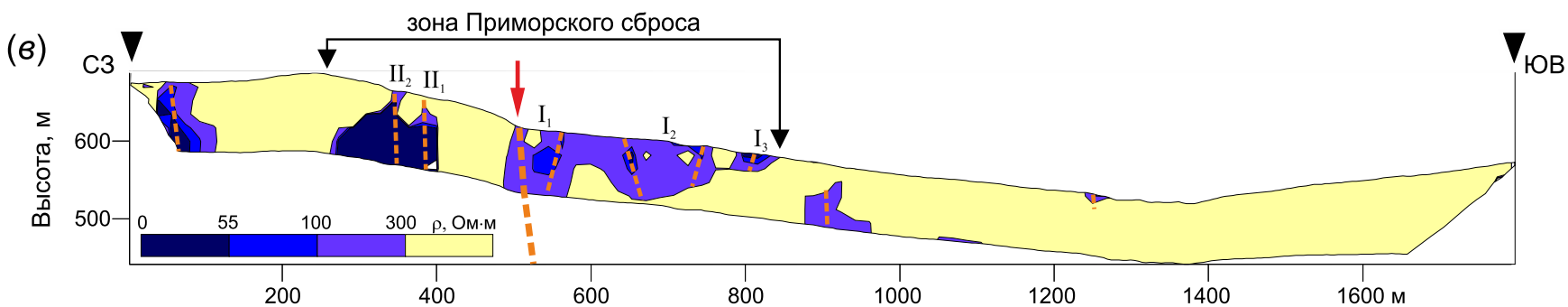

(2) $700,0 \quad 80.0 \quad 160 \quad 240 \quad 320$

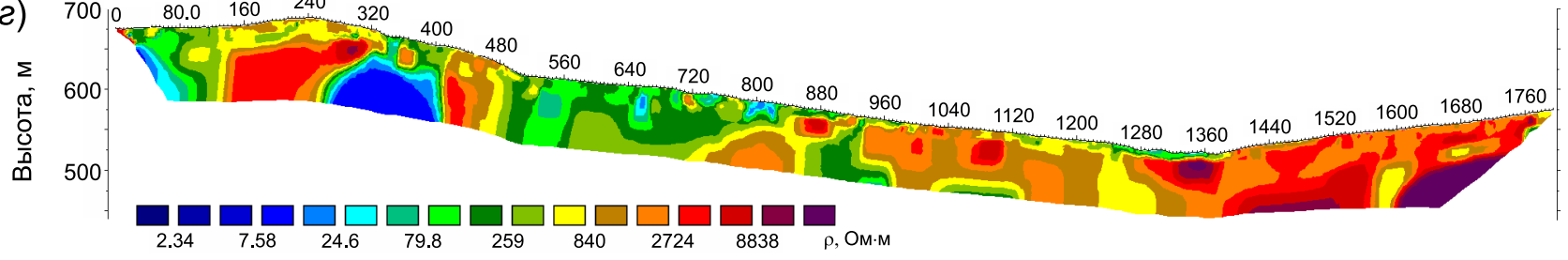

(d)

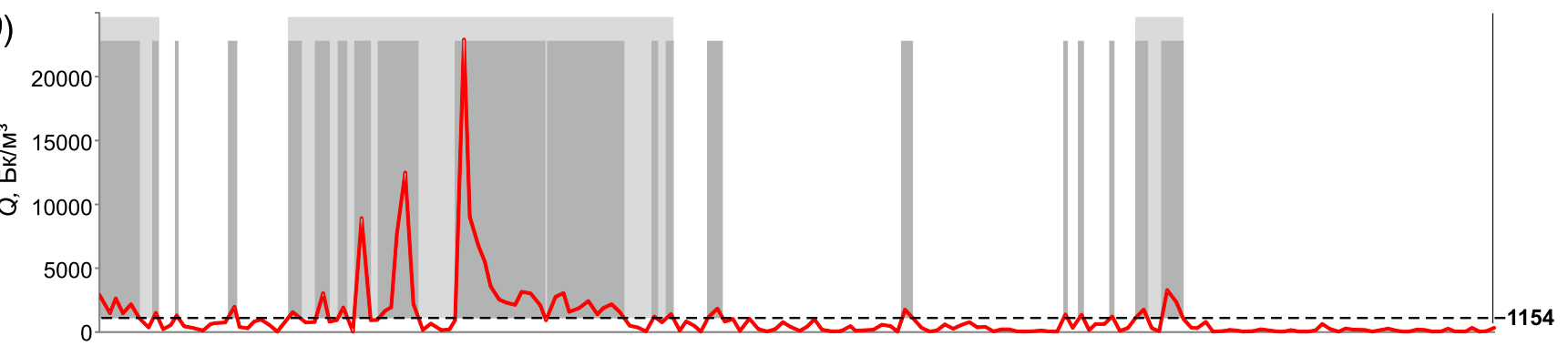

Рис. 3. Результаты исследований зоны динамического влияния регионального Приморского сброса на Бугульдейской площади.

(a) - положение главного сместителя сброса (пунктир) и профиля геофизических исследований (концы обозначены треугольниками) на космоснимке. (б) - гистограмма распределения величин УЭС $(\rho)$, полученных при электротомографических измерениях: N - частота встречаемости значений $\rho$; цифры вверху - величины $\rho$, ограничивающие области значений УЭС (окрашены разными оттенками фиолетового цвета), соответствующие характерным уровням нарушенности пород. (в) - модифицированный геоэлектрический разрез, построенный с изолиниями, которые проведены по значениям $\rho$, выделенным при статистической обработке электротомографических измерений (рис. 3 , б). Римские цифры - индексы пяти локализованных областей с низкими значениями УЭС; пунктир - оси наиболее низкоомных участков в их пределах. Красная стрелка - положение главного сбросового сместителя. (2) - геоэлектрический разрез, построенный со стандартным набором изолиний параметра $\rho$. $(\partial)$ - график изменения объемной активности почвенного радона (Q) вдоль профиля. Пунктир - уровень среднего арифметического величин Q, измеренных для профиля; участки темно-серого цвета - отрезки профиля с аномальными значениями параметра объемной активности радона $\left(\mathrm{Q}>\mathrm{Q}_{\mathrm{cp}}\right)$; участки светло-серого цвета - приразломные аномалии почвенного радона.

Fig. 3. The zone of dynamic influence of the regional Primorsky fault (Buguldeika site).

(a) - space image showing the positions of the main normal fault plane (dashed line) and the geophysical profile (the ends are marked by triangles). (б) - distribution of SER values $(\rho)$ according to electrical resistivity tomography measurements: $\mathrm{N}$ - frequency of occurrence of $\rho$ values; numbers at the top - $\rho$ values that limit the SER ranges (different shades of purple) and correspond to the characteristic 
degrees of rock disturbance. $(\theta)$ - modified geoelectrical profile, and the isolines based on the $\rho$ values from statistical processing of electrical resistivity tomography measurements (see Fig. 3 б). Roman numerals - indices of the five local areas with low SER values; dashed line - axis of the lowest SER sites within the local areas. Red arrow - position of the main fault plane. (2) - geoelectrical profile constructed with a standard set of isolines of the parameter $\rho$. $(\partial)$ - changes in the volumetric activity of soil radon (Q) along the profile. Dashed line level of the arithmetic mean of $Q$ values measured for the profile; dark grey - segments of the profile with anomalous $Q$ values $(Q>Q$ mean);

light grey - near-fault anomalies of soil radon activity.

(a)

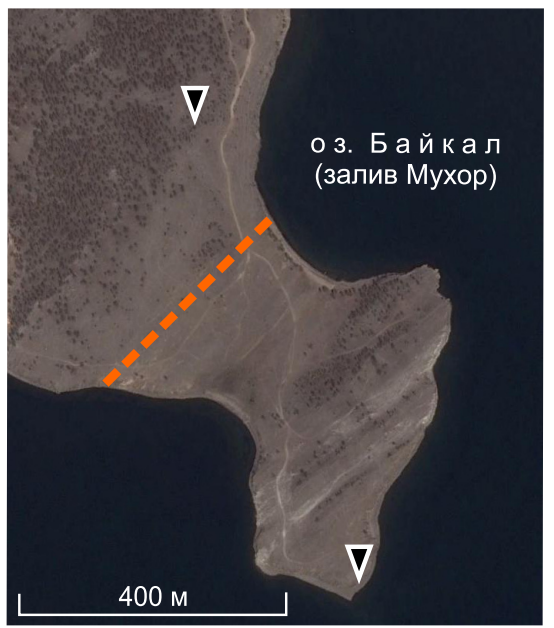

(б)
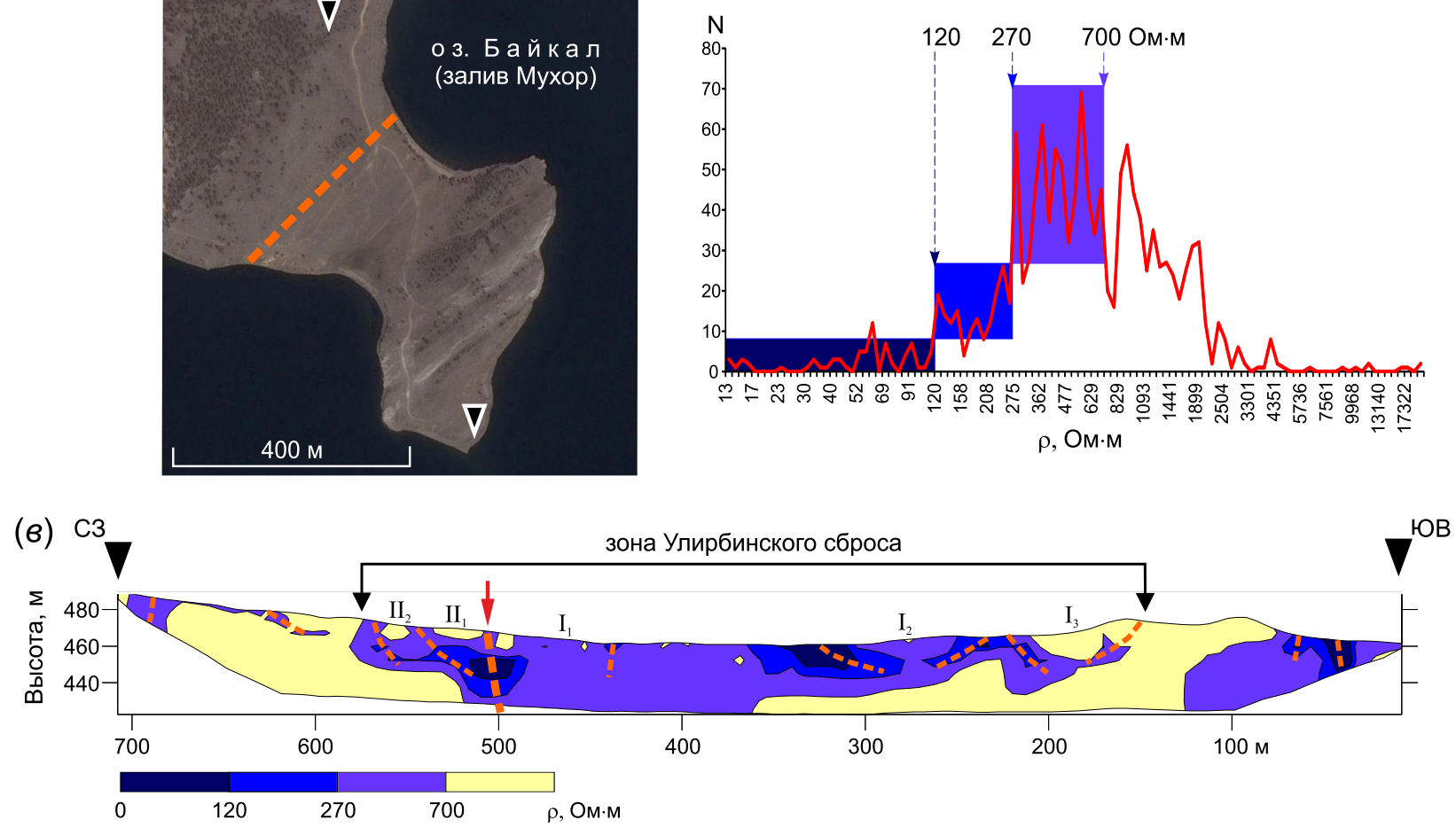

(2)

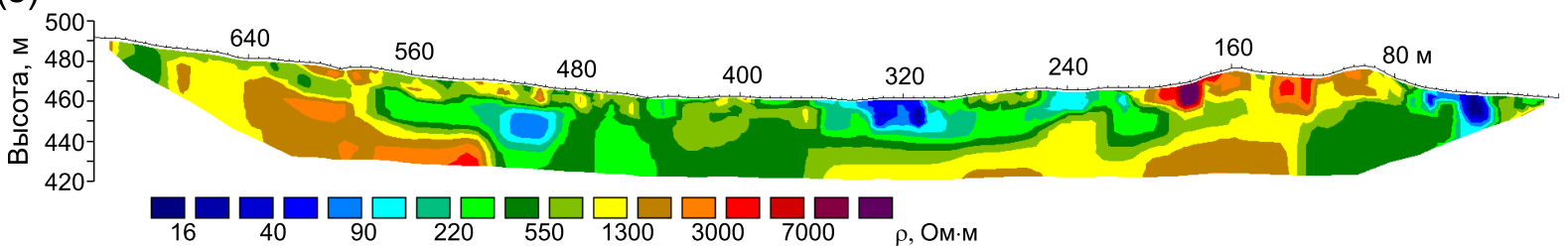

(d)

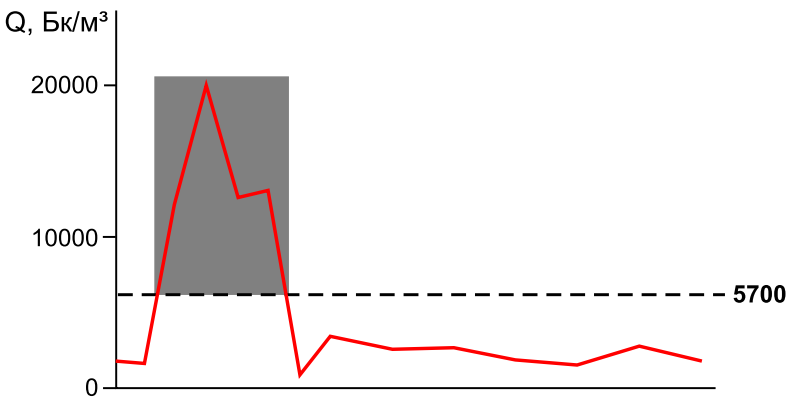

Рис. 4. Результаты исследований зоны динамического влияния локального Улирбинского сброса на Улирбинской площади. Названия рисунков $4, a-\partial$, и обозначения к ним аналогичны представленным в подписи к рис. 3.

Fig. 4. The zone of dynamic influence of the local Ulirba fault (Ulirba site). See the legend to Fig. 3. 
(a)

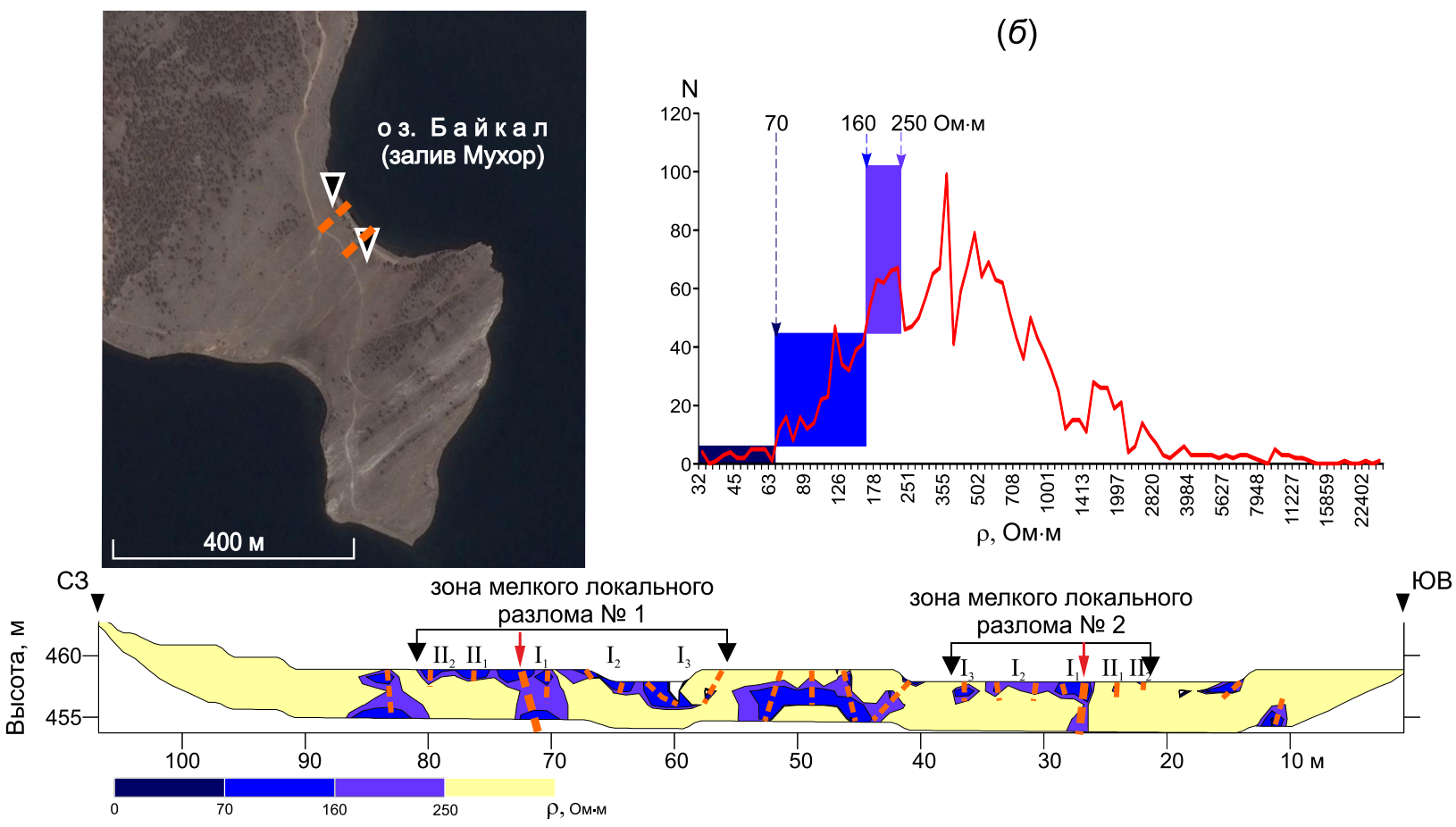

(2)

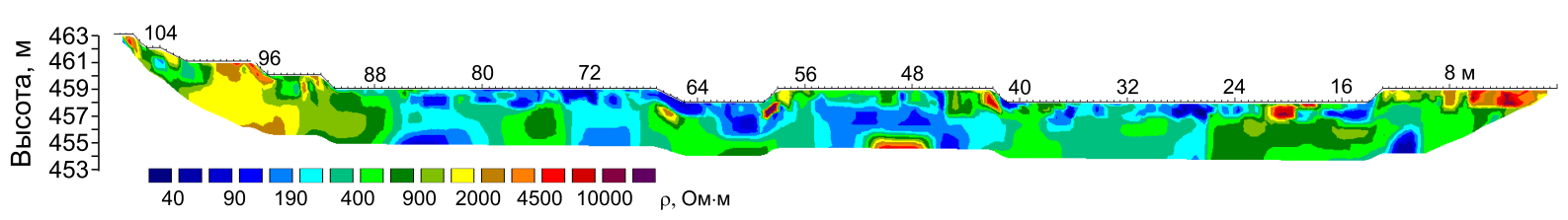

Рис. 5. Результаты исследований зон динамического влияния двух мелких локальных разломов на Улирбинской площади. Названия рисунков 5, a-2, и обозначения к ним аналогичны представленным в подписи к рис. 3.

IFig. 5. The zones of dynamic influence of two small local faults on the Ulirba site. See the legend to Fig. 3.

Малоглубинная электротомография осуществлялась при помощи многоэлектродной станции сопротивлений «Скала-48». Методика измерений $\rho$ была отработана и опробована в ходе предшествовавших работ в Западном Прибайкалье [Zaripov, 2013]. При работе на Улирбинской и Онтхойской площадях использовалась последовательность подключения электродов, соответствующая симметричной установке Шлюмберже с расстоянием между электродами 0.5 и 5.0 м. Вариации данного параметра позволили изменять глубину зондирования с целью равноценного изучения разломов разного ранга. Так, шаг между электродами 0.5 м обеспечил возможность детального исследования поля УЭС до глубины 4 м вдоль профилей, пересекающих мелкие локальные разломы (см. рис. 5, 2). Шаг в 5 м позволил провести зондирование зон локальных Улирбинского (см. рис. 4, 2) и Онтхойского (рис. 6, e) разломов до глубины 40 м. На профиле, пересекающем региональный Приморский сброс, использовалась установка Реверс поле-диполя с электродом В, вынесенным в «бесконечность», что обеспечило возможность изучения разреза до глу- бины 80 м. Таким образом, применение «гибкой» методики зондирований позволило изменять практически на порядок глубину электротомографической съемки, если на порядок менялась длина изучаемого разлома.

Инверсия данных электротомографии производилась робастным способом с применением программного обеспечения Res2DInv [Loke, 2010]. Геоэлектрические разрезы, построенные с применением заложенного в программе способа определения уровней изолиний УЭС, представлены на рис. 3,$2 ; 4,2 ; 5,2 ; 6, e$, для каждой из площадей. Кроме этого, все материалы электротомографии были обработаны с применением тектонофизического подхода, подробно описанного в предыдущей статье [Seminsky et al., 2016]. Применение данной методики позволило построить геоэлектрические разрезы с выделением участков (см. рис. 3,6 ; рис. 4,6 ; рис. 5, в; 6, 2), нарушенность которых соответствует трем главным стадиям разломообразования (ранней, поздней, полного разрушения), и, тем самым, выявить положение внешних границ разломной зоны в совокупно- 


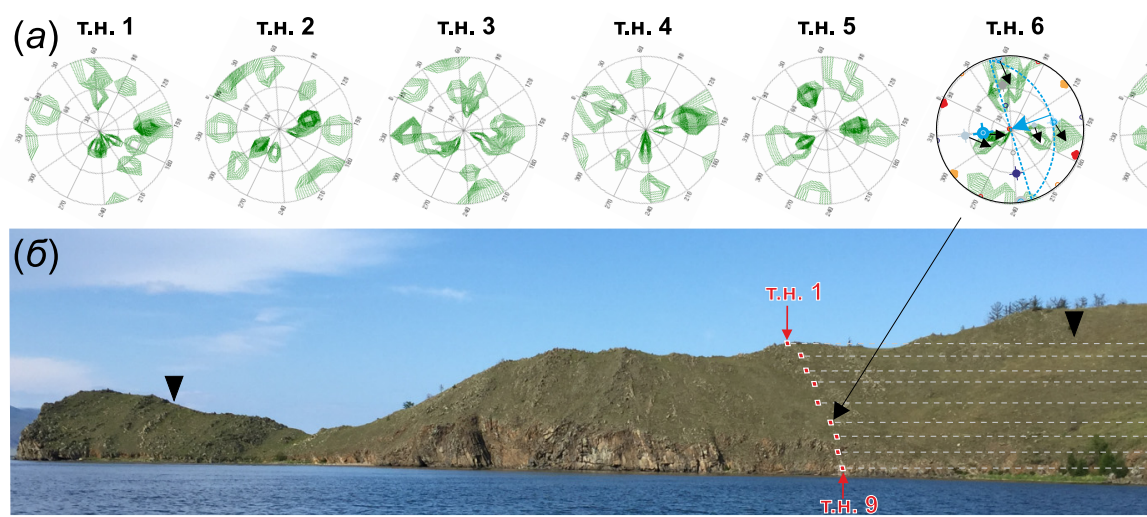

(2)
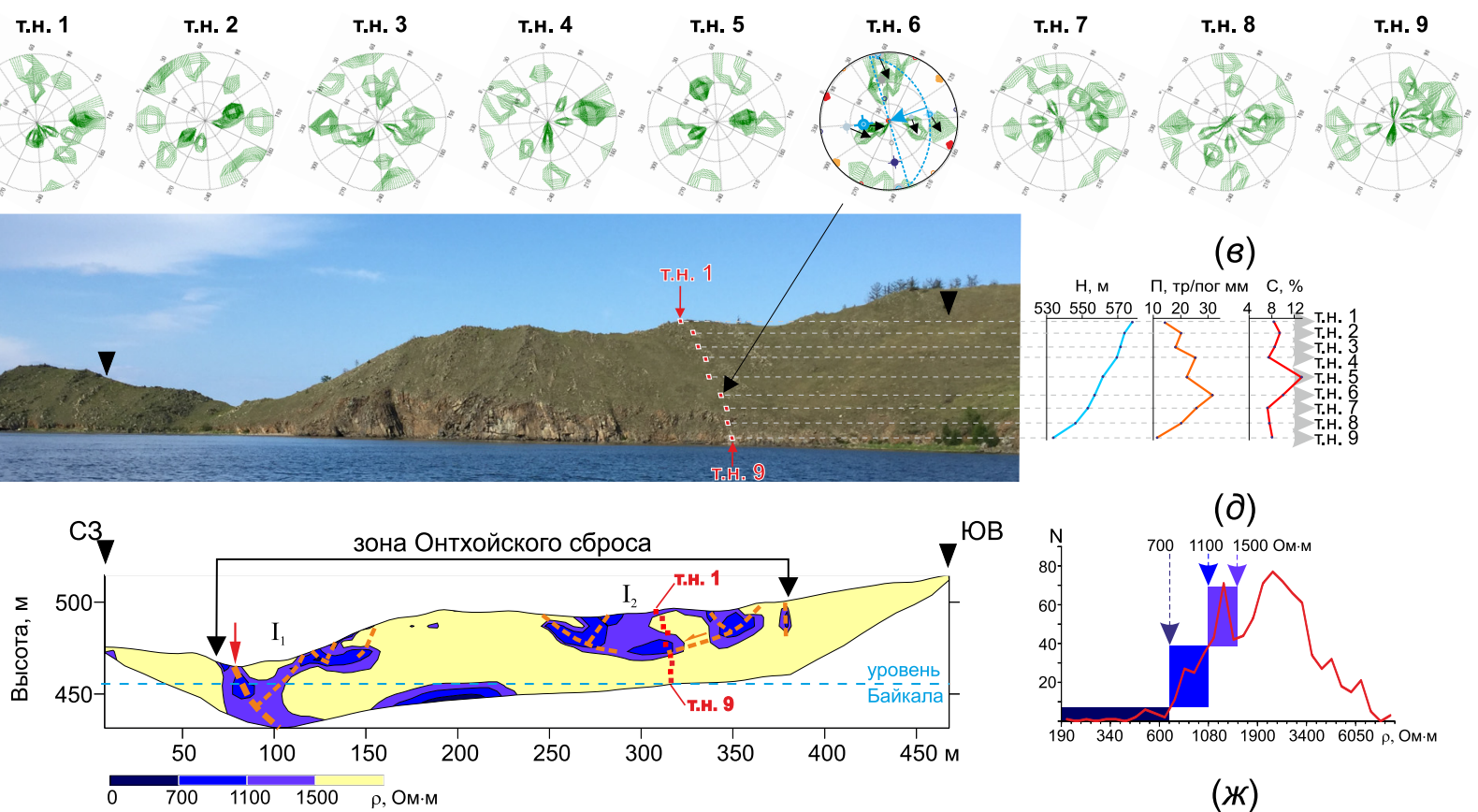

(8)

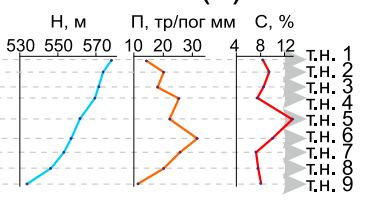

$(\partial)$

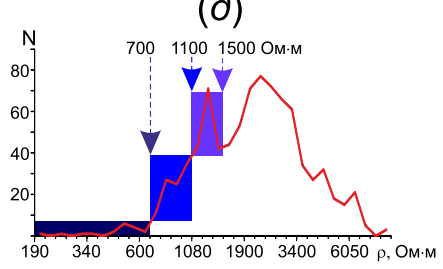

(ж)
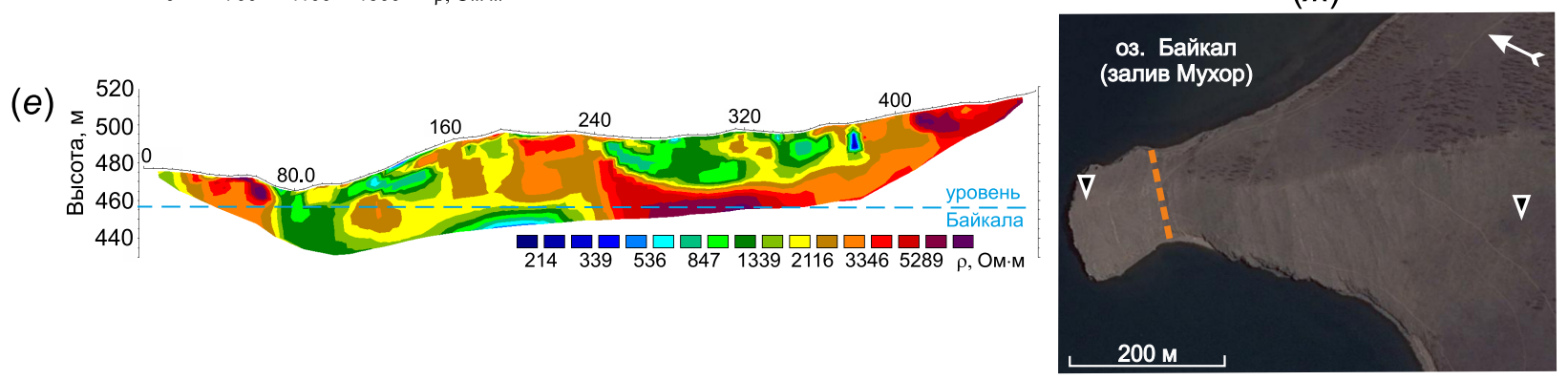

Рис. 6. Результаты исследований зоны динамического влияния локального Онтхойского сброса на Онтхойской площади.

(a) - круговые диаграммы трещиноватости, построенные по результатам массовых замеров (по 20 трещин) в 9 пунктах структурных наблюдений, составляющих профиль, положение которого показано на рис. 6, б. Для т.н. 6 показано решение о положении разлома (синий пунктир) и векторе смещения (синяя стрелка), полученное в результате удовлетворительного совпадения максимумов диаграммы с эталонным трафаретом (набор разноцветных символов - полюсов идеализированного парагенезиса, представленного на рис. 6 в работе [Seminsky, 2014]). Черная точка с черной стрелкой - центр максимума полюсов трещин (черный кружок), который соответствует одной из разрывных систем (начало стрелки) эталонного трафарета. (б) - фотография мыса Онтхой. Черные треугольники - точки профиля электротомографии; красные точки - положение пунктов структурных наблюдений. (в) - вариации вдоль профиля структурных наблюдений высоты рельефа $(\mathrm{H})$, плотности трещин в одном погонном метре коренного выхода (П) и средней интенсивности максимума на круговой диаграмме (С). (2) - модифицированный геоэлектрический разрез, построенный с изолиниями, которые проведены по значениям $\rho$, выделенным при статистической обработке электротомографических измерений (рис. 6, , ). Римские цифры - индексы двух локализованных областей с низкими значениями УЭС; пунктир - оси наиболее низкоомных участков в их пределах. Красная стрелка - положение главного сбросового сместителя. Красные точки - пункты структурных наблюдений. ( $\partial$ ) - гистограмма распределения величин УЭС ( $\rho$ ), полученных при электротомографических измерениях: $\mathrm{N}$ - частота встречаемости значений $\rho$; цифры вверху - величины $\rho$, ограничивающие области значений УЭС (окрашены разными оттенками фиолетового цвета), соответствующие характерным уровням нарушенности пород. (e) - геоэлектрический разрез, построенный со стандартным набором изолиний параметра р. (ж) - положение главного сместителя сброса (пунктир) и профиля электротомографии (концы обозначены треугольниками) на космоснимке.

Fig. 6. The zone of dynamic influence of the local Ontkhoi fault (Ontkhoi site).

(a) - circle diagrams based on mass measurements (20 fractures) taken on nine structural observation sites (see the profile in Fig. 6 6). For observation point 6, shown are the fault position solution (blue dashed line) and the displacement vector (blue arrow) as a result of the satisfactory coincidence of the maximums in the diagram and the reference pattern (symbols of various colours - poles of the idealized paragenesis shown in Fig. 6 in [Seminsky, 2014]). The black circle with the black arrow marks the center of the maximum of the poles of fractures (black circle) which corresponds to one of the fracture systems (arrow start) of the reference pattern. (б) - photo of Cape Ontkhoi. Black triangles - points of the electrical resistivity tomography profile; red circles - positions of the structural observation points. $(\theta)$ - along the structural observation profile, variations in: $\mathrm{H}$ - elevation, $\Pi$ - density of fractures in one linear meter of the baserock outcrop, C - average intensity of the maximum in the circle diagram. (2) - modified geoelectrical profile constructed with isolines based on the $\rho$ values from statistical processing of electrical resistivity tomography measurements (see Fig. $6 \partial$ ). Roman numerals - indices of the two local areas with low SER values; dashed line - axis of the lowest SER sites within the local areas. Red arrow - position of the main fault plane. Red circles - positions of the structural observation points. $(\partial)$ - distribution of SER values $(\rho)$ according to electrical re- 
sistivity tomography measurements: $\mathrm{N}$ - frequency of occurrence of $\rho$ values; numbers at the top - $\rho$ values that limit the SER ranges (different shades of purple) and correspond to the characteristic degrees of rock disturbance. ( $e$ ) - geoelectrical profile constructed with a standard set of isolines of the parameter $\rho$. $(\mathcal{H})$ - space image showing the positions of the main normal fault plane (dashed line) and the electrical resistivity tomography profile (the ends are marked by triangles).

сти с особенностями ее внутреннего строения (см. рис. 1, $а-б$ ).

Для установления уровней изолиний параметра $\rho$, которые соответствуют нарушенности пород на трех главных стадиях разломообразования, строится гистограмма частоты встречаемости значений УЭС в выборке, полученной для каждого профиля (см. рис. 3, б; 4, б; 5, б; 6, д). Согласно методике [Seminsky et al., 2016], это три первых от оси ординат уровня на нисходящей ветви графика (окрашены цветом). Следует отметить, что в рассматриваемых здесь случаях третий уровень не охватывает всю область максимальных значений УЭС, как это было характерно для гистограмм из цитированной методической статьи. Его правая граница $(300,700$, 250 и 1500 Ом·м - см. рис. 3-6, соответственно) проводится в области глубокого минимума, который является значимым, так как представлен более чем одним значением УЭС.

Для ранее описанных сравнительно коротких профилей [Seminsky et al., 2016], не выходящих далеко за границы разломной зоны, подобные величины УЭС (третий уровень) представляли всю вершинную часть гистограммы. Они доминировали в выборке, так как большая часть геоэлектрического разреза была представлена периферийной подзоной парагенетически связанных трещин, а участки, не принадлежащие к разломной зоне (нисходящая ветвь гистограммы), имели ограниченное распространение. В противоположность этому на приведенных здесь длинных профилях слабонарушенный массив (желтый цвет) представляет большую часть разреза (см. рис. 3,6 ; 4, 6; 5, в; рис. 6, г). Как следствие, соответствующие ему значения УЭС доминируют на гистограммах (см. рис. 3,$6 ; 4,6 ; 5,6 ; 6$, $\partial$ ), образуя вторую, более широкую, часть срединного максимума в совокупности с нисходящей ветвью графика.

Геоэлектрические разрезы (см. рис. 3, в; 4, в; 5, в и рис. 6,2$)$, полученные с использованием гистограмм $\rho$ (см. рис. $3,6,4 ; 8,5$; 8 и рис. 6,2 ), генерализуют исходные распределения УЭС (см. рис. 3,2 ; 4, 2; 5,2 и рис. 6, ). Они являются главным фактическим материалом для дальнейшего анализа, направленного на определение характера проявления мелких локальных, локальных и регионального разломов в поле распределения УЭС.

Вспомогательные методы применялись для определения положения главных сместителей изучаемых разломных зон, установления их морфогене- тического типа и внешних границ, что было необходимо для заложения положения электротомографических профилей, а также качественной интерпретации геоэлектрических разрезов. Анализ рельефа на местности и с использованием космоснимков применялся на всех площадях, так как позволял по уступам рельефа и его пониженным формам (впадины, ложбины и пр.) устанавливать положение сбросовых сместителей и примерные границы зон их влияния (см. рис. $2 ; 3, a ; 4, a ; 5 a$; рис. $6,6, ж)$.

На площадях, перекрытых рыхлыми отложениями (Бугульдейская, Улирбинская), подобные характеристики разломных зон устанавливались по размерам и строению аномалий почвенного радона, выявленных, согласно [Seminsky, Demberel, 2013; Seminsky et al., 2014], при анализе материалов профильной радоновой съемки (см. рис. $3, \partial ; 4, \partial$ ). В сравнительно простых случаях (см. рис. $4, \partial$ ) зона активного сброса маркируется сплошным макси-

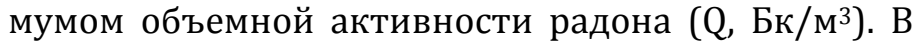
более сложной структурной ситуации (см. рис. $3, \partial$ ) он является прерывистым и состоит из близко расположенных аномалий радона $\left(\mathrm{Q}>\mathrm{Q}_{\mathrm{cp}}\right)$, каждая из которых соответствует главному или второстепенному разрыву в разломной зоне.

На площадях с удовлетворительной обнаженностью горных пород (Онтхойская, Улирбинская) применялись геолого-структурные методы исследования разрывной структуры. Кроме известных приемов изучения разрывных нарушений, был использован метод спецкартирования разломной структуры, базирующейся на парагенетическом анализе трещиноватости, не содержащей признаков смещений, но повсеместно распространенной в тектонически активных регионах [Seminsky, 2014, 2015]. В рамках метода анализируются главные характеристики трещинной сети: плотность (количество на пог. метр), сложность (количество систем) и массовый замер элементов залегания трещин. В первом приближении первый из параметров определяет интенсивность действовавших в породах напряжений, второй - сложность деформационной истории, а массовый замер после специальной обработки - тип разломной зоны, к которой относится трещиноватый массив.

С целью определения последней, наиболее важной, характеристики для пункта с массовым замером строится круговая диаграмма трещиноватости (рис. $6, a$ ). Затем она сопоставляется с эталонными 
трафаретами (т.н. 6 на рис. 6, a), каждый из которых был предварительно теоретически обоснован и отражает набор разрывных систем, формирующихся в сбросовой, взбросовой, надвиговой или сдвиговой зоне [Seminsky, 2014]. Удовлетворительное совпадение эталонной и природной трещинных сетей позволяет сделать вывод о типе и пространственном положении разломной зоны, к которой принадлежит изучаемый коренной выход.

В итоге применения описанных методов на Бугульдейской, Улирбинской и Онтхойской площадях было пройдено (с разной степенью детальности) 3000 пог. м профилей электротомографической съемки и 2000 пог. м радоновой съемки, сделано девять массовых замеров трещин и проведено геолого-структурное обследование всех обнажений коренных пород вблизи геофизических профилей. Этот фактический материал послужил основой для представленного ниже анализа, тогда как к обобщению результатов привлекались опубликованные данные, полученные ранее при многолетних геолого-геофизических исследованиях разломов Приольхонья, и в частности на Онтхойской и Улирбинской площадях [Seminsky et al., 2008, 2013; Cheremnykh, 2010; Seminsky, Bobrov, 2012].

\section{3. АНОМАЛИИ УЭС, СВЯЗАННЫЕ С РАЗНОРАНГОВЫМИ СБРОСОВЫМИ ЗОНАМИ НА БУГУЛЬДЕЙСКОЙ, УЛИРБИНСКОЙ И ОНТХОЙСКОЙ ПЛОЩАДЯХ}

На Бугульдейской площади профиль электротомографии пересек полностью Бугульдейско-Чернорудский грабен в том месте, где главный сместитель бортового регионального Приморского сброса отчетливо выражен в рельефе и в поле эманаций радона. На рис. 3 видно, что падающему на юговосток разлому соответствует характерный уступ и наибольший пик объемной активности радона (см. рис. $3, a, 8-\partial)$. Сопутствующая ему серия близкорасположенных, но менее интенсивных аномалий позволяет выявить границы разломной зоны, ширина которой составляет $\approx 500$ м. На профиле выделено еще две аномалии радона - в его начале и в том месте (интервал 1330-1400 м), где профиль пересек Тырганский сброс, ограничивающий грабен с юговостока.

Геоэлектрический разрез, построенный по стандартной методике (см. рис. 3, 2), демонстрирует резко неоднородное распределение УЭС, что затрудняет определение границ зоны Приморского сброса и положения вторичных разрывных нарушений. Напротив, уровни изолиний 55, 100 и 300 Ом•м, выделенные по гистограмме параметра $\rho$ (см. рис. 3, б), отчетливо подчеркивают эти особенности его структуры (см. рис. 3, в). Аномалия, ассоци- ирующаяся с главным сместителем сброса, имеет на глубине ширину 80 м, но в пределах висячего крыла резко увеличивается к поверхности до 360 м. В выделенной области имеют место участки, уровень нарушенности которых соответствует поздней стадии развития разломной зоны. Их форма вместе с внешним контуром всей области пониженных УЭС позволила показать пунктиром оси наиболее нарушенных участков. Как правило, этим осям соответствуют максимумы на профиле радоновой съемки (см. рис. $3, \partial$ ), что косвенно подтверждает их разломное происхождение.

Левее описанной части разреза находится вторая по размерам аномалия УЭС (см. рис. 3, в), отличающаяся наиболее высоким уровнем электрической проводимости. Судя по наличию небольших уступов в рельефе и, главным образом, серии сближенных максимумов концентрации почвенного радона (см. рис. 3, д), эта аномалия также имеет разломную природу. Однако существенный размер (130 м) участка, в котором уровень нарушенности соответствует стадии полного разрушения, свидетельствует о том, что дезинтеграция породного массива имеет не только тектоническое происхождение. Зоны древних разломов Приольхонья подвержены глубокому выветриванию [Dombrovskaya, 1973], мелкодисперсные продукты которого, как и глинка трения, имеют очень низкие значения УЭС [Palacky, 1989] - до единиц Ом•м. Тектониты, выветрелые подобным образом, обнажаются в зоне главного сместителя Приморского сброса в 25 км северо-восточнее рассматриваемого профиля (рис. 7).

Следовательно, несмотря на обособленное в пределах разреза положение рассматриваемой аномалии УЭС, вызвавшая ее образование разломная структура относится к зоне регионального Приморского сброса. На глубине она может соединяться с описанной выше зоной главного сместителя, образующей в пределах разреза наиболее крупную аномалию электропроводности. Дополнительным подтверждением данного предположения является единая аномалия радона (интервал 240740 м, см. рис. 3, д), к которой, согласно отработанному методическому подходу [Seminsky, Demberel, 2013; Seminsky et al., 2014], должны относиться участки с $Q<Q_{c p}$, если их размер меньше соседних интервалов профиля с аномальной концентрацией радиоактивного газа в почве $\left(\mathrm{Q}>\mathrm{Q}_{\mathrm{cp}}\right)$.

Кроме описанных выше аномалий УЭС, на рассматриваемом разрезе есть еще несколько небольших интервалов, в пределах которых уровень нарушенности пород соответствует разломному (см. рис. 3, в). Один из них находится в начале профиля и, судя по аномалии радона, действительно имеет тектоническое происхождение. Аномалия 


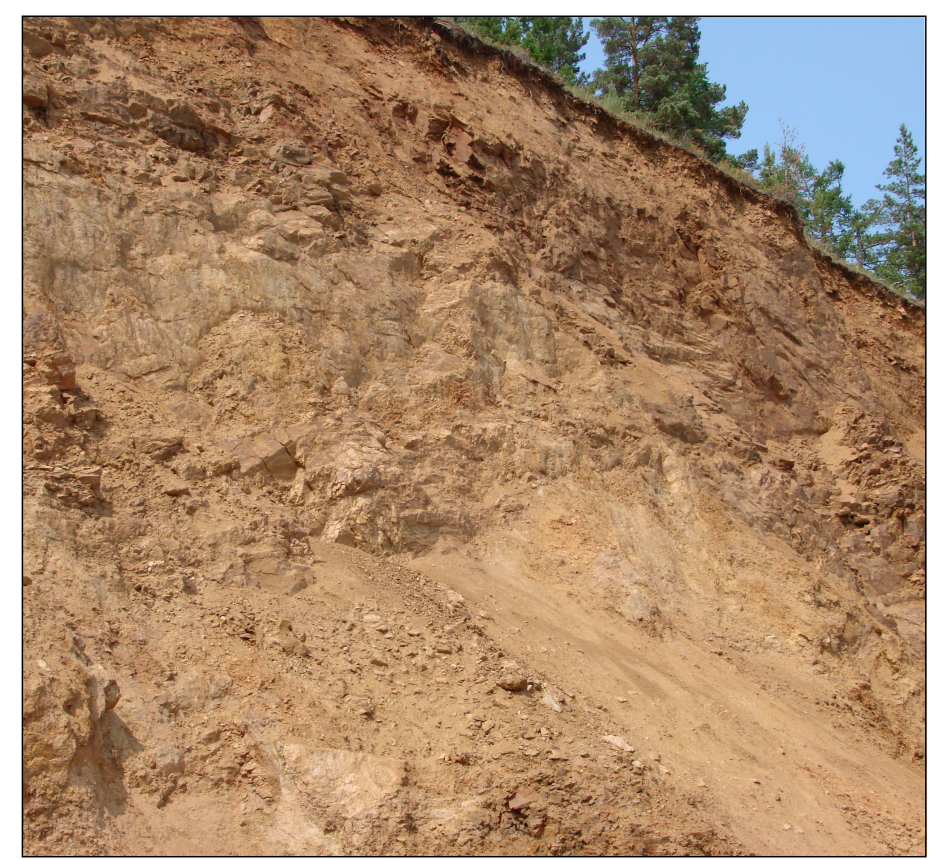

УЭС в средней части профиля (интервал 880-960 м) не выделяется в поле газовых эманаций и, следовательно, не связана с активным разрывным нарушением. Возможно, это древний разлом с выветрелой зоной тектонитов, подобный дизъюнктивам, которые были вскрыты бурением в центральной части Бугульдейско-Чернорудского грабена - в 20 км северо-восточнее рассматриваемого профиля [Dombrovskaya, 1973]. Следующая аномалия УЭС располагается у поверхности в интервале 12401270 м и относится к зоне Тырганского сброса (см. рис. 3, в). Несмотря на ее небольшие размеры, этот бортовой разлом довольно отчетливо проявлен уступом в рельефе и серией сближенных пиков - на эманационном профиле (см. рис. $3, \partial$ ). Видимо, рассматриваемый сегмент Тырганского сброса не наследует зону древних тектонитов и не отличается высокой интенсивностью подвижек в позднем кайнозое, способной сформировать мощную зону дробления и глинки трения.

Таким образом, тектонофизический подход к обработке данных электротомографии позволил установить, что с региональным Приморским сбросом в верхних 80 м геологического разреза связана широкая $(\approx 600$ м) зона повышенной электрической проводимости. Она имеет сложное прерывистое строение и отличается в крыльях по форме и уровням УЭС, что обусловлено состоянием внутренней структуры крупного дизъюнктива.

Большая часть приразломной аномалии повышенной электропроводности располагается в висячем крыле, демонстрируя неравномерное уменьшение размеров и интенсивности от главного сместителя к периферии (интервал 480-840 м, см.
Рис. 7. Фотография зоны выветривания по тектонитам главного сместителя Приморского сброса (район пос. Еланцы в Приольхонье).

Fig. 7. Photo: the tectonite weathering zone in the main fault plane of the Primorsky fault (the site near the settlement of Yelantsy, Olkhon region). рис. 3, в). Волнистая форма нижней границы и локализация минимумов УЭС позволяют выделить три области, в пределах которых уровень нарушенности пород достигает поздней стадии разломообразования. Первая из них $\left(\mathrm{I}_{1}\right)$ уходит на глубину и ассоциируется с главным сместителем Приморского разлома, а также участком повышенной нарушенности, ось которого наклонена в противоположную сторону. У поверхности, между этим участком и сместителем, имеет место слабонарушенный блок размером $25 \times 25$ м. Аналогичным строением (две падающие навстречу друг другу оси нарушенных участков и менее раздробленный массив между ними) характеризуется смежная часть разломной зоны $\left(\mathrm{I}_{2}\right)$, у которой нижняя граница аномалии УЭС находится на глубине 80 м. Наконец, третий - периферийный - сегмент разломной зоны $\left(\mathrm{I}_{3}\right)$ выражен в виде приповерхностной линзы интенсивно нарушенных пород, размер которой по горизонтали равен 60 м, а по вертикали -25 м.

В лежачем крыле регионального Приморского сброса приразломная аномалия повышенной электропроводности представлена величинами $\rho$, наименьшими для изученного разреза (см. рис. 3, ). У поверхности она проявляется в виде двух «апофиз» $\left(\mathrm{II}_{1}\right.$ и $\left.\mathrm{II}_{2}\right)$, переходящих с глубиной в единое тело, имеющее у основания разреза ширину $\approx 150$ м. Аномалия подобной формы и интенсивности может быть обязана своим происхождением двум разрывным структурам, активизировавшимся в зоне древних тектонитов, замещенных на глубинах 20-80 м низкоомными продуктами выветривания. Это в совокупности с уже описанными признаками 
дает возможность отнести ее к зоне Приморского сброса, а также предполагать сочленение с аномалией висячего крыла на глубине.

На Улирбинской площади было проведено изучение геоэлектрического строения локального Улирбинского сброса (см. рис. 4, а) и двух мелких локальных разломов, располагающихся вблизи его главного сместителя (см. рис. 5, $a$ ).

Зона локального Улирбинского сброса была пересечена полностью профилем электротомографии, протягивающимся от оконечности одноименного мыса на север-северо-запад через главную разломную впадину и субпараллельные ей узкие ложбины (см. рис. $4, a$ ). Результаты геолого-структурных исследований [Cheremnykh, 2010; Seminsky, 2015] позволили установить их разломное происхождение, а также определить положение главного сместителя, характеризующегося наклоном в юго-восточном направлении. На профиле эманационной съемки ему соответствует непрерывная аномалия почвенного радона шириной 60 м (см. рис. 4, д).

Геоэлектрический разрез, построенный по стандартной методике (см. рис. 4,2$)$, отличается сложным строением, особенностью которого является чередование высокоомных блоков и низкоомных областей, представленных, соответственно, повышенными и пониженными формами рельефа. Несмотря на извилистый характер их границ, грибоподобную область высокой электропроводности, представленную впадиной в центральной части профиля, можно связать с зоной Улирбинского сброса. Геоэлектрический разрез, построенный с использованием уровней изолиний 120, 270 и 700 Ом•м, выделенных по гистограмме параметра $\rho$ (см. рис. 4, б), позволяет установить границы этой приразломной аномалии, а также выделить особенности ее внутреннего строения.

Аномальная зона у поверхности имеет ширину 430 м, но у основания разреза сужается до 160 м, т.е. примерно в три раза (см. рис. 4, в). Главный сместитель Улирбинского сброса маркируется наиболее крупным минимумом УЭС, в пределах которого нарушенность пород, как и ожидается, достигает стадии полного разрушения. Зона резко асимметрична, поскольку более чем на 80 \% принадлежит к висячему крылу. В его пределах по форме нижней границы и положению участков с аномально низким УЭС выделяется три интенсивно нарушенные области - $\mathrm{I}_{1}, \mathrm{I}_{2}$ и $\mathrm{I}_{3}$.

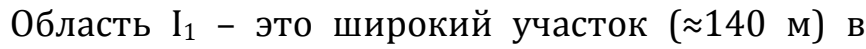
центре разломной зоны, нарушенность которого на всю глубину зондирования соответствует ранней стадии разломообразования (см. рис. 4, в). Лишь у поверхности в пределах небольшого блока на отметке 440 м породы дислоцированы на уровне поздней стадии разломообразования. Область $\mathrm{I}_{2}$ имеет кардинально отличное строение. Она не распространяется до основания разреза, но содержит два вытянутых участка с нарушенностью, соответствующей стадии полного разрушения. Их оси, судя по форме изолиний, наклонены навстречу друг другу и выполаживаются с глубиной, оконтуривая линзовидный блок менее нарушенных пород у поверхности. Область I3 подобна по строению, но нарушена в меньшей степени. Это проявляется в ее сравнительно небольших размерах и слабой выраженности крайнего участка повышенной нарушенности, который не достигает поверхности.

В лежачем крыле Улирбинского сброса приразломная зона аномальных УЭС имеет ширину 150 м и охватывает верхние 20 м геоэлектрического разреза (см. рис. 4, в). В ее пределах выделяются две области с высокой нарушенностью пород ( $\mathrm{II}_{1}$ и $\mathrm{II}_{2}$ ), оси которых наклонены к главному сместителю. Между этими областями, а также областью $\mathrm{II}_{1}$ и главным сместителем у поверхности располагаются небольшие блоки с высоким УЭС, не соответствующим уровню нарушенности пород в пределах разломной зоны.

Мелкие локальные разломы Улирбинской площади были изучены вблизи главного сместителя одноименного сброса, зона которого, маркирующаяся интенсивной аномалией почвенного радона (см. рис. 4, д), пересечена профилем электротомографии длиной 110 м (см. рис. 5). Геоэлектрический разрез, построенный традиционным способом (см. рис. 5, 2), сложен для выделения разломных структур ввиду неоднородного распределения УЭС в пределах интенсивно нарушенного участка земной коры. Уровни изолиний 70, 160 и 250 Ом•м, выделенные на основе анализа гистограммы параметра $\rho$ (см. рис. 5, б), представляют более перспективную основу для интерпретации.

Так, форма и взаимное расположение многочисленных аномалий низкого УЭС на модифицированном геоэлектрическом разрезе (см. рис. 5, в) позволяют выделить, по крайней мере, две области их концентрации, которые можно считать обусловленными проявлением небольших локальных разломов. Одна из этих областей имеет ширину 25 м и представляет зону мелкого локального разлома № 1, а другая - зону разлома № 2 шириной 16 м. Обе аномалии имеют грибоподобную форму с плоской «шляпкой» у поверхности и «ножкой», уходящей от нее вниз с небольшим отклонением от вертикали. Оси, проведенные в этих частях аномалий, наклонены навстречу друг другу и ассоциируются с главными сместителями изучаемых разломов. Субгоризонтальные части аномалии в висячих крыльях отличаются в два раза большими размерами по сравнению с размерами аномальных областей в лежачих крыльях и содержат большее ко- 
личество участков с уровнем УЭС, соответствующим поздней стадии разломообразования.

Онтхойская площадь является полигоном для наших многолетних работ [Seminsky et al., 2008, 2013; Cheremnykh, 2010; Seminsky, Bobrov, 2012; Seminsky, 2015], направленных на исследование характера проявления в геофизических полях одноименного сброса. Разлом отчетливо выражен ложбиной в рельефе (см. рис. 6, б, ж), а также зонами дробления и трещиноватости в обнажениях горных пород. Так, мелкий локальный разлом в зоне сместителя Онтхойского сброса был изучен ранее посредством электротомографии в рамках 100метрового профиля с тектонофизической интерпретацией полученных материалов [Seminsky et al., 2016]. Эти данные будут привлекаться к обсуждению представленных в статье материалов (раздел 4).

Ниже рассматриваются результаты электрических зондирований разреза до глубины 40 м по 500-метровому пересечению зоны Онтхойского локального разлома в целом (см. рис. 6, 2, е, ж). Геоэлектрический разрез м. Онтхой, построенный традиционным способом (см. рис. 6, e), свидетельствует о наличии двух крупных областей пониженного электрического сопротивления. Первая из них занимает разрез на всю глубину в интервале 70-160 м и приурочена к главному сместителю Онтхойского сброса, выраженному глубокой ложбиной. Вторая располагается на некотором удалении и занимает верхнюю половину разреза в пределах субгоризонтальной части гребня м. Онтхой (интервал 240-380 м).

Модифицированный геоэлектрический разрез (см. рис. 6, 2) с уровнями изолиний 700, 1100 и 1500 Ом•м, установленными по гистограмме параметра $\rho$ (см. рис. 6, д), позволяет более четко оконтурить эти области и установить особенности их строения. Уровень 700 Ом•м выделяет лишь узкую полосу у основания разреза (отметка 200 м). Ориентация и форма мелких изоклинальных складок, обнажающихся над этой полосой в береговом обрыве, позволяют предположить, что ее возникновение каким-то образом связано со структурами раннепалеозойского сжатия земной коры региона в направлении СЗ-ЮВ. Уровни изолиний 1100 и 1500 Ом·м выделяют две описанные выше области ( $\mathrm{I}_{1}$ и $\mathrm{I}_{2}$ ) как представленные породами, у которых степень нарушенности на периферии соответствует ранней, а в приосевых частях - поздней стадии разломообразования.

Область $\mathrm{I}_{1}$ состоит из двух пространственно связанных фрагментов, первый из которых (интервал 70-120 м) выделяет зону главного сместителя Онтхойского сброса, выполаживающуюся с глубиной (см. рис. 6, 2). Второй фрагмент (интервал 120-
150 м), располагающийся в близповерхностной части висячего крыла, характеризуется сложным строением и сочленяется с первым на глубине $\approx 25$ м. Над участком сочленения выделяется блок слабонарушенных пород.

Область $\mathrm{I}_{2}$ находится в верхней половине геоэлектрического разреза и имеет в целом линзообразную форму (см. рис. 6, 2). Это подчеркивается положением осей, проведенных в его нижней части по минимумам УЭС в соответствии с формой изолиний. «Бескорневой» характер, линзовидная форма и отдаленное расположение рассматриваемой области по отношению к главному сместителю Онтхойского сброса послужили причинами проведения целенаправленных геолого-структурных исследований для подтверждения ее тектонического происхождения.

Согласно материалам обследования крутых склонов м. Онтхой, в пределах изучаемой области под тонким (до нескольких десятков сантиметров) и несплошным почвенным покровом залегают гнейсы и гранитогнейсы, наклоненные под углом 60-70 к юго-востоку (см. рис. 6, б). Это не позволяет объяснить линзовидную форму аномалии электропроводности наличием низкоомных слабосцементированных или скальных пород, характеризующихся субгоризонтальным залеганием.

Природу рассматриваемой аномалии удалось установить в результате структурных исследований, проведенных путем изучения многочисленных, но небольших обнажений скальных пород на западном склоне мыса Онтхой (см. рис. 6, б). Здесь не были зафиксированы зоны дробления, крупные тектонические зеркала и разрывы со штрихами скольжения, свидетельствующие о наличии явно выраженных разломных сместителей. В связи с этим исследования были направлены на анализ «немой» трещиноватости и концентрировались вдоль профиля, который полностью пересек область $\mathrm{I}_{2}$ в ее центральной части.

В девяти коренных выходах, располагающихся на профиле примерно в 20 м друг от друга, было проведено целенаправленное исследование сети мелких разрывов с целью реконструкции динамической обстановки их формирования. Для этого, согласно разработанной методике спецкартирования [Seminsky, 2015], на первом этапе работ для каждой точки наблюдения определялось количество трещин на 1 пог. м коренного выхода (П), был выполнен массовый замер элементов их залегания и строилась круговая структурная диаграмма (см. рис. 6, a). Далее определялась средняя интенсивность максимума на диаграмме (C, \%), низкие значения которой свидетельствуют о хаотичности трещинной сети, а высокие - о ее большей системности [Burzunova, 2014]. 
Как видно по вариациям параметров П и С (см. рис. 6, в), их наиболее высокие значения характерны для центральной сравнительно пологой части профиля (см. график изменения высоты), где он пересекает участок низких УЭС у основания линзовидной области $\mathrm{I}_{2}$. Следовательно, высокая электрическая проводимость здесь определяется интенсивной нарушенностью пород трещинами, причем их сеть является наиболее системной. Последнее отчетливо видно при сопоставлении рисунка изолиний на диаграммах трещиноватости (см. рис. $6, a)$. В отличие от хаотических сетей большинства изученных коренных выходов, в пунктах 5 и 6 они характеризуются простотой и внешним сходством. Использование, согласно методике спецкартирования [Seminsky, 2015], эталонных трафаретов показало (см. рис. $6, a$, т.н. 6), что согласно взаимному положению максимумов, их разбросам и угловым взаимоотношениям изучаемые трещинные сети сформировались в пологозалегающей зоне растяжения $\left(315^{\circ} \angle 30^{\circ}\right)$.

Таким образом, близповерхностная область пониженных УЭС на м. Онтхой $\left(\mathrm{I}_{2}\right)$ является грабенообразной структурой, ограниченной зонами повышенной трещиноватости, выполаживающимися с глубиной. Сбросовый характер движений и ориентация растяжения в направлении СЗ-ЮВ дают основание предположить, что эта структура развивается в одном поле напряжений с Онтхойским разломом и, возможно, связана с ней парагенетически.

Итак, применение тектонофизического подхода к обработке материалов электротомографии по Бугульдейской, Улирбинской и Онтхойской площадям показало его эффективность для выделения и исследования внутреннего строения аномалий УЭС, связанных с разноранговыми сбросовыми зонами Приольхонья. Несмотря на различие масштабных рангов, каждая из них характеризуется комплексным проявлением на геоэлектрическом разрезе. Сложная форма и специфическое распределение низких величин УЭС в пределах приразломных аномалий определяются не типами пород, а их состоянием (обводнение) и степенью нарушенности (трещиноватость, «рыхлые» тектониты, тонкодисперсные продукты выветривания), т.е. в конечном итоге - состоянием внутренней структуры сбросовых зон в широком понимании данного термина.

\section{4. ОБОБЩЕННАЯ ГЕОЭЛЕКТРИЧЕСКАЯ МОДЕЛЬ СБРОСОВОЙ РАЗЛОМНОЙ ЗОНЫ}

Главные элементы модифицированных геоэлектрических разрезов. Применение единого тектонофизического подхода к обработке и интерпретации электротомографических профилей, пересекающих разноранговые сбросы Бугульдейско-Чернорудского грабена, послужило основой для установления общих закономерностей их проявления в поле УЭС. Фактическим материалом для сопоставления являются модифицированные геоэлектрические разрезы (см. рис. 3,$6 ; 4,8 ; 5,6 ; 6,2$ ), на которых в однотипной цветовой гамме выявлены приразломные аномалии высокой электропроводности и особенности их внутреннего строения. Так, три уровня изолиний УЭС на каждом из разрезов, несмотря на различие в абсолютных значениях, оконтуривают аномальные участки, в пределах которых уровень нарушенности пород соответствует периферийной подзоне парагенетически связанной трещиноватости (фиолетовый цвет), подзоне разрывов 2-го порядка и повышенной трещиноватости (темно-синий цвет) и подзоне главного сместителя (темнофиолетовый цвет).

На примере сбросов видно (см. рис. 3,$8 ; 4,8 ; 5$, в; $6,2)$, что в пределах изученной приповерхностной части земной коры участки с одним уровнем нарушенности не образуют сплошного поля и содержат блоки пород, относящиеся по параметру $\rho$ к предыдущему уровню. В меньшей степени это касается периферийной подзоны парагенетически связанной трещиноватости, внешний контур которой часто является непрерывной границей разломной зоны в целом (см. рис. 4, в; рис. 5, в - зона разлома 1). В некоторых случаях наличие непрерывного контура можно подразумевать на глубине (см. рис. 3, в), тогда как в других структурных ситуациях (см. рис. 6,2 ) для отнесения отдаленных аномалий к одной разломной зоне необходимо привлекать дополнительные доказательства.

Участки массива, нарушенность которых соответствует двум другим уровням, в большинстве случаев узко локализованы или образуют цепочки, что позволило использовать их контуры и/или положение для выделения осей аномалий УЭС (см. пунктирные линии рис. 3,$6 ; 4,6 ; 5,6 ; 6,2)$. Согласно теоретическим основам тектонофизического подхода к интерпретации электротомографической съемки [Seminsky et al., 2016], эти пунктиры отражают положение разломных структур. В пределах изученных сбросовых зон это подтвердилось для всех главных сместителей, положение которых было известно априори, а также для тех случаев, когда присутствие второстепенных разрывных нарушений косвенно подтверждается максимумами эманаций радона (см. рис. 3,$2 ; 4, \partial$ ) или данными специальных геолого-структурных исследований (см. рис. 6, a-2).

Описание геоэлектрической модели сбросовой зоны. Сопоставление геоэлектрических разрезов (см. рис. 3,$8 ; 4,8 ; 5, в$ и 6, 2) на предмет расположения разрывных нарушений, формы границ и распреде- 


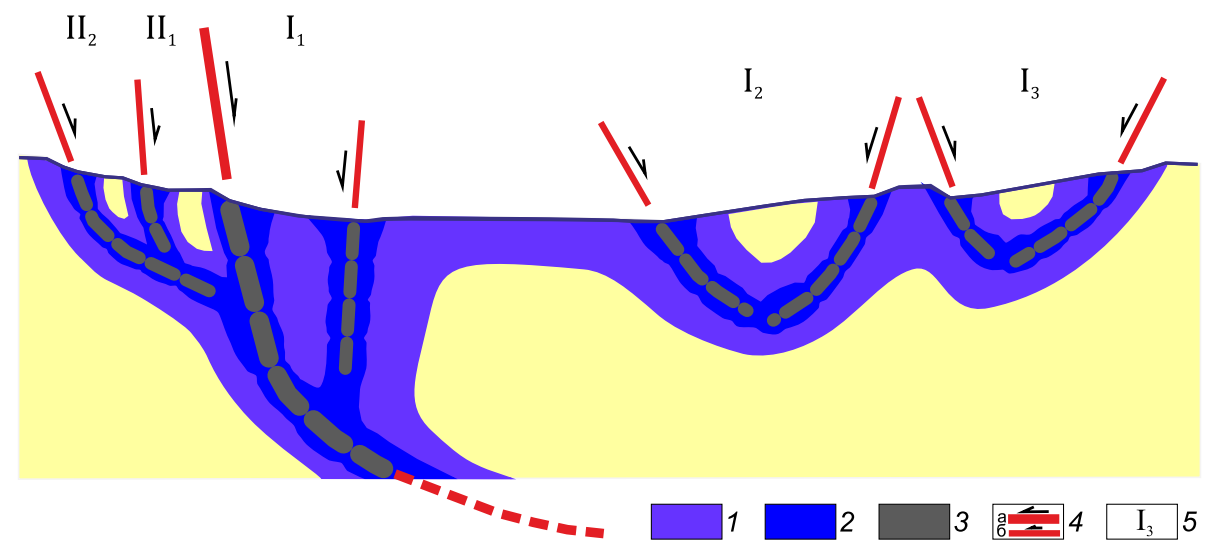

Рис. 8. Обобщенный геоэлектрический разрез (модель) сбросовой разломной зоны.

1-3 - участки характерных значений УЭс, которые соответствуют уровням нарушенности пород в пределах: 1 - периферийной подзоны парагенетически связанной трещиноватости, 2 - подзоны разрывов 2-го порядка и повышенной трещиноватости, 3 подзоны главного сместителя; 4 - положение и кинематика главного сместителя (а) и разрывов 2-го порядка (б) (пунктир предполагаемое); 5 - индексы локализованных областей, в пределах которых имеют место наиболее низкие значения УЭС.

Fig. 8. Generalized geoelectrical profile (model) of the normal fault zone.

1-3 - sites with typical SER values corresponding to the degrees of rock disturbance in: 1 - peripheral subzone of paragenetically related fracturing, 2 - subzones of the $2^{\text {nd }}$-order fractures and increased fracturing, 3 - subzone of the main fault plane; 4 - positions and kinematics of the main fault plane (a) and the $2^{\text {nd }}$-order fractures (б) (dashed line - assumption); 5 - indices of the local areas with the lowest SER values.

ления участков с тремя аномальными уровнями нарушенности свидетельствует, что сбросовые зоны Приольхонья по большому счету проявляются одинаково в поле УЭС, несмотря на различия масштабных рангов, структурной позиции в разных бортах грабена и механических свойств дислоцированных пород. Это позволило предложить геоэлектрическую модель сбросовой разломной зоны, представленную в виде обобщенного распределения аномальных УЭС в разрезе приповерхностной части земной коры (рис. 8). Форма и строение аномальной зоны определяются наличием пяти областей $\left(\mathrm{I}_{1}, \mathrm{I}_{2}, \mathrm{I}_{3}, \mathrm{II}_{1}\right.$ и $\left.\mathrm{II}_{2}\right)$, в которых происходит наиболее интенсивная деструкция породного массива в условиях растяжения.

Область $\mathrm{I}_{1}$ представляет сбросовый сместитель вместе с близлежащим участком висячего крыла и, как следствие, является главной, всегда присутствующей в структуре приразломной аномалии электропроводности (рис. 8). В отличие от большинства других областей, она распространяется на всю мощность геоэлектрического разреза (см. рис. $3,8 ; 4,8 ; 5,8 ; 6,2)$, хотя не всегда является наиболее крупной по поперечному размеру. У аномалии Онтхойского сброса рассматриваемая область обнаруживает явную тенденцию к выполаживанию с глубиной (см. рис. 6, 2). По степени нарушенности пород область $\mathrm{I}_{1}$ представляет подзону парагенетически связанных трещин, в которой имеются локальные участки более интенсивной деструкции. Они могут располагаться в центральной части рассматриваемой области (см. рис. 3 , в; рис. 5, в зона разлома 2) или маркировать каждый из составляющих ее разломов - главный сместитель и второстепенный разрыв, являющийся, как правило, противосбросом (см. рис. 4, в; 6, 2; 5, в - зона разлома 1).

Область $\mathrm{I}_{2}$ располагается в висячем крыле и представляет следующий после области $\mathrm{I}_{1}$ участок приразломной аномалии по размерам и степени нарушенности пород (рис. 8). Эта область отличается линзовидным обликом, имеет характерную выпуклую форму нижней границы и не нарушает разрез на всю глубину (см. рис. 3 , в; 4, в; 5, в). Согласно перечисленным признакам, участок Онтхойского разреза, располагающийся в верхней части интервала 240-370 м (см. рис. 6, 2), следует отнести к приразломной аномалии УЭС, несмотря на его отдаленное положение относительно области главного сместителя $\mathrm{I}_{1}$. По строению область $\mathrm{I}_{2}$, повидимому, представляет грабен с относительно слабо дислоцированным центральным блоком и бортовыми зонами повышенной нарушенности. Зоны в некоторых случаях выполаживаются с глубиной навстречу друг другу, что придает рассматриваемой области линзообразную форму (см. рис. $4,8 ; 6,2)$.

Область $\mathrm{I}_{3}$ представляет периферийную часть приразломной аномалии УЭС в висячем крыле (рис. 8). Она практически по всем признакам подобна области $\mathrm{I}_{2}$, но меньше по размерам для подавляющего большинства изученных сбросовых 
зон (рис. 3 , в; 4, в; 5, в - зона разлома 2). В некоторых случаях рассматриваемая область включает не все элементы структуры (см. рис. 4, 8; 6, 2), что можно считать признаком незавершенности ее формирования.

Области $\mathrm{II}_{1}$ и $\mathrm{II}_{2}$ являются элементами приразломной аномалии УЭС в лежачем крыле сброса и представляют интенсивно нарушенные зоны второстепенных разрывов (рис. 8). У локального Онтхойского разлома эти области не выделяются (см. рис. 6, 2). В остальных ситуациях оси зон субвертикальны или наклонены к главному сместителю (см. рис. 3. в; 4, в; 5, в). Характер проявления рассматриваемых областей различен на отдельных геоэлектрических разрезах и, по-видимому, определяется степенью развитости их внутренней структуры. В одном случае области $\mathrm{II}_{1}$ и $\mathrm{II}_{2}$ могут составлять части единой аномалии нарушенности, не содержащей в масштабе исследования менее нарушенные блоки (см. рис. 5 - зона разлома 1). В другой структурной ситуации подобные блоки между рассматриваемыми областями имеют место лишь в близповерхностой части разреза (см. рис. 4, в). Наконец, они могут полностью отделять одну (см. рис. 5 - зона разлома 2) или обе (см. рис. 3) области от аномалии главного сместителя.

Таким образом, главными элементами обобщенной геоэлектрической модели сбросовых зон являются низкоомная область главного сместителя, большая часть которой находится в висячем крыле и распространяется на всю глубину разреза, а также четыре приповерхностных аномалии УЭС по две с разных сторон от сместителя (рис. 8). Это обусловливает грибообразную и асимметричную форму приразломной аномалии, в каждом крыле которой имеют место различным образом развитые низкоомные области. В целом степень их проявления в плане интенсивности, ширины и глубины больше в висячем крыле по сравнению с лежачим и уменьшается от главного сместителя к периферии. Масштабный ранг разлома влияет на абсолютные размеры отдельных элементов аномалии, но относительное положение и соотношения параметров низкоомных областей по большому счету сохраняются для сбросов локального и регионального ранга.

Механизм формирования сбросовых зон как причина единообразия их проявления в поле УЭС. Приведенной геоэлектрической модели соответствуют аномалии параметра $\rho$, выделенные ранее при описании тектонофизического подхода к анализу данных электротомографии для мелкого локального разрыва в зоне сместителя Онтхойского сброса и разлома локального ранга в районе пр. Ольхонские Ворота [Seminsky et al., 2016]. Характерные для Приольхонья асимметричные грибоподобные анома- лии с неоднородным внутренним строением представляют, по-видимому, достаточно распространенное выражение сбросовых зон на малоглубинных геоэлектрических разрезах. Об этом свидетельствуют опубликованные материалы электротомографических исследований [Fazzito et al., 2009; Komolafe et al., 2012; Moisidi et al., 2012; Pedrera et al., 2012; Al-Zubedi et al., 2015; Zhu et al., 2017], на которых даже без применения тектонофизического подхода к обработке полевых измерений проявляются отмеченные выше черты приразломных аномалий. Их пологие (в верхней части разреза) формы, обычно объясняемые наличием линз и прослоев низкоомных осадков («вещественный» фактор), могут в свете изложенных выше материалов по Приольхонью получить иную, «структурную», трактовку.

Сходная форма проявления в поле УЭС сбросовых зон из разных структурно-вещественных обстановок свидетельствует об обобщающем характере предложенной геоэлектрической модели. Причину этого следует искать в единстве механизма формирования региональных и локальных разломов, который рассмотрен ниже для условий растяжения в верхней («хрупкой») части земной коры. С позиций тектонофизики можно выделить два главных типа сбросовых зон, образующихся под действием горизонтальных или вертикальных сил (рис. 9).

Строение зоны (или системы) растяжения, формирующейся в процессе перемещения блоков в горизонтальном направлении (рис. 9, б), характеризуется наличием главного сместителя, выполаживающегося с глубиной. Движение вдоль листрической поверхности приводит к растяжению висячего блока с образованием системы полуграбенов и грабенов. Представленная на рис. 9, б, компилятивная модель строения такой системы растяжения соответствует структуре аномалии УЭС в висячем крыле сбросовой зоны (см. рис. 8). Листрическая форма разломов западного плеча Байкальского рифта и, в частности, сбросов Приольхонья известна из работ предшественников [Pleshanov, Romazina, 1981; Mats, 1993; Mats et al., 2001]. Более того, Н.О. Кожевников [Kozhevnikov, 2015] при интерпретации электроразведочных измерений методами ЗСБ установил в пределах Бугульдейско-Чернорудского грабена наличие пологозалегающих проводящих тел, которые могут отражать положение наиболее глубоких (>100 м) сегментов сместителей у сбросовых зон регионального ранга.

Строение сбросовой зоны, формирующейся при перемещении блоков в вертикальном направлении (рис. 9, a), отличается сравнительно плоской поверхностью главного сместителя. Она является итогом эволюции опережающих сбросов и про- 
(a)

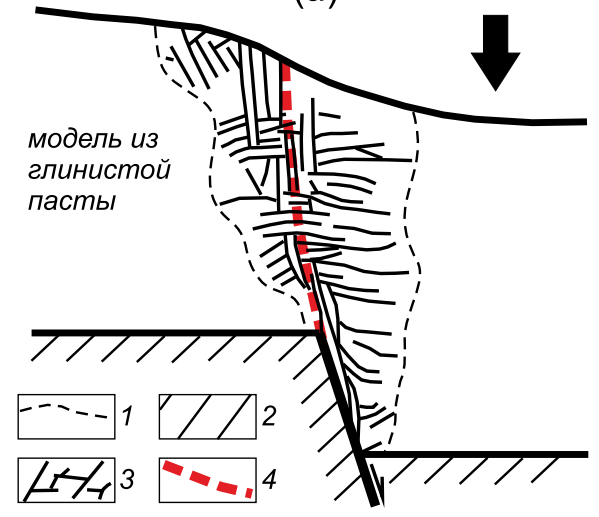

(б)

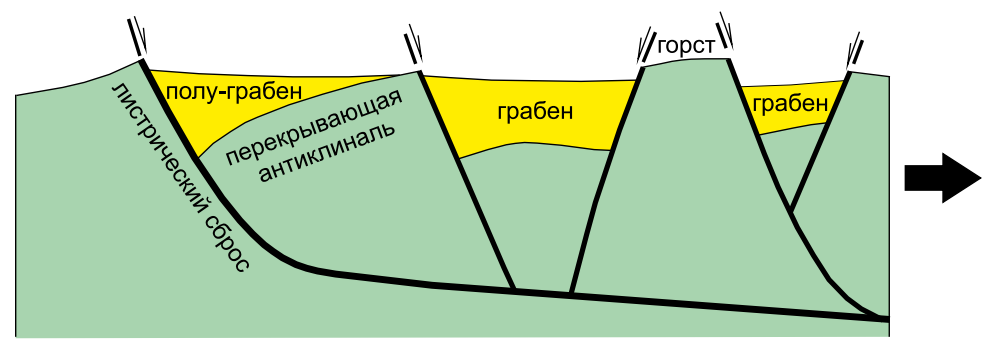

Рис. 9. Характерные примеры строения сбросовых зон, формирующихся под действием вертикально (a) и горизонтально (б) ориентированных внешних сил (черная двусторонняя стрелка).

(a) - схема разрывов, представляющих сбросовую зону, формирующуюся в упругопластичной модели при вертикальном перемещении штампа экспериментальной установки (по [Bokun, 1985] с дополнениями). (б) - обобщенная схема главных элементов строения сбросовой зоны (системы), формирующейся при скольжении блоков по сместителю листрической формы (по [Вurg, 2018]). 1 - граница зоны разрывообразования; 2 - штампы; 3 - разрывы 2-го порядка; 4 - положение будущего магистрального сместителя.

Fig. 9. Typical structural schemes of normal fault zones formed due to the effects of external forces oriented vertically $(a)$ or horizontally (б) (black two-side arrow).

(a) - scheme of fractures representing the normal fault zone that forms in the elastic-plastic model during vertical movement of the experimental installation's stamp (modified after [Bokun, 1985]). (6) - generalized scheme showing the main elements in the structure of the normal fault zone (system) formed when the blocks slip along the listric-shape main fault plane (after [Burg, 2018]). 1 - boundary of the zone of fracturing; 2 - stamps; 3 - 2nd-order fractures; 4 - position of the future major fault plane.

тивосбросов, осложняющих строение обоих крыльев. Судя по данным физического моделирования [Bokun, 1985; Grigoriev et al., 1987; Sherman et al., 1992; Patton et al., 1998], в пределах лежачего блока зона представляет сеть вторичных сбросов и расширяется к поверхности, что соответствует структуре аномалии УЭС у большинства изученных в Приольхонье разломов.

Таким образом, предложенная на примере Приольхонья геоэлектрическая модель может иметь широкое применение для диагностики обстановок и структур растяжения земной коры, поскольку ее строение контролируется общими закономерностями формирования сбросовой зоны, имеющей листрическую форму. Структура аномалии УЭС в лежачем крыле отражает веер вторичных разломов, образующихся при субвертикальных движениях в сбросовой зоне, которая у поверхности круто наклонена к горизонту. Строение аномалии УЭС в висячем крыле отражает систему линзоподобных грабенов, формирующихся вследствие субгоризонтального перемещения блока по подстилающей его сравнительно пологой поверхности главного сместителя.

Влияние условий разломообразования на характер проявления сбросовых зон в поле УЭС. Несмотря на сравнительно высокий уровень обобщения, предложенная геоэлектрическая модель в большей или меньшей степени отличается от картины распределения УЭС в зонах конкретных сбросов в связи с различием характера структурно-вещественной неоднородности деформируемых массивов и динамических условий разломообразования. Это имеет место даже в сравнительно однотипных условиях Приольхонья и выражается в интенсивности проявления и пространственных соотношениях отдельных составляющих приразломной аномалии УЭС.

Так, «вещественный» фактор может существенно повлиять на форму и строение аномалии, если геологический разрез содержит, к примеру, прослои низкоомных осадков, обводненных горизонтов или, наоборот, высокоомных включений мерзлых пород. В скальном массиве различие в прочности или физическом состоянии отдельных породных разновидностей приведет к изменению соотношений величин $\rho$ в однотипных элементах геоэлектрической модели по отношению к их проявлению в механически однородной толще. Примером подобной ситуации можно считать аномалию УЭС в лежачем крыле Приморского сброса (см. рис. $3,8)$, высокая интенсивность и непропорционально большие размеры которой связываются с наличием древней зоны дробления, заполненной низко- 
омными тонкодисперсными продуктами выветривания.

«Структурный» фактор, проявляющийся в нарушенности породного массива сетью древних разрывов, может привести к их активизации в поле растяжения, что изменит взаимное расположение или соотношения параметров отдельных элементов аномалии УЭС. Этим, по-видимому, объясняется глубокое (почти до середины разреза) проникновение периферийных областей $\mathrm{I}_{3} \mathrm{y}$ аномалий, связанных с мелкими локальными разломами (см. рис. 5, в), по сравнению с обычно более развитым грабеном I2 (см. рис. 3, в; 4, в). Более существенным влиянием на форму аномалии УЭС характеризуется наследование древних структурных неоднородностей поверхностью главного сбросового сместителя. Подобная ситуация возможна в зоне Онтхойского сброса (см. рис. 6, в), который начинает выполаживаться уже на глубине 30 м от поверхности. Скорее всего, это связано с кайнозойской активизацией палеозойского надвига, существование которого можно предполагать по складкам волочения, обнажающимся в висячем крыле. Реализующийся в этом случае механизм растяжения полностью соответствует первой модели (рис. $9, a$ ), что объясняет отсутствие аномальных значений параметра $\rho$ в лежачем крыле, а также рассредоточенный характер приразломной аномалии в целом.

Фактор динамической обстановки существенно влияет на строение системы растяжения и, как следствие, ее отражение в поле УЭС. Следует полагать, что геоэлектрическая модель, представленная на рис. 8, должна быть справедлива для многих регионов. Обусловливающий ее механизм формирования листрических сбросов широко проявлен в обстановках растяжения верхней части земной коры, где имеет место система субгоризонтальных неоднородностей. Однако модель не применима для условий развития листрических разломов в более податливом породном массиве или при реализации растяжения через систему плоских сбросов.

\section{5. ЗАКЛЮЧЕНИЕ}

Применение тектонофизического подхода к обработке и интерпретации профилей малоглубинной электротомографии на примере региональных, локальных и мелких локальных сбросов центральной части Байкальского рифта позволило установить, что связанные с ними аномалии электрической проводимости имеют подобный в качественном отношении вид. В самой верхней (<100 м) части коры сбросовая зона выражается низкоомной аномалией, имеющей грибоподобный поперечный профиль и неоднородное внутреннее строение. Аномалия асимметрична и при полноценном развитии включает пять областей максимальной электропроводности, из которых три принадлежат к висячему и две - к лежачему крылу. Четыре периферийные области располагаются у поверхности, тогда как центральная, вслед за главным сместителем сбросовой зоны, проникает на всю глубину разреза.

Подобие имиджей разноранговых сбросовых зон на геоэлектрическом разрезе определяется общими закономерностями разломообразования, имеющими место в процессе скольжения по сместителю листрической формы. Крутонаклоненной приповерхностной части соответствует центральная зона пониженных сопротивлений и низкоомные зоны вторичных разрывов лежачего крыла. Над пологим более глубоким сегментом формируется система линзоподобных грабенов висячего крыла, каждому из которых соответствует область аномальной электропроводности. Причинами низких УЭС в пределах участков интенсивного разрывообразования могут быть обводнение и/или насыщенность тонкодисперсными продуктами разрушения, образующимися при скольжении блоков и выветривании.

Идеализированная модель проявления сбросовой зоны в поле УЭС (см. рис. 8) является основой для интерпретации геоэлектрических разрезов, получаемых с целью картирования разломной структуры, скрытой под рыхлыми наносами в областях растяжения земной коры. Вместе с тем, конкретные геоэлектрические имиджи могут отличаться от предложенной модели вследствие специфики структурно-вещественной неоднородности деформируемых массивов и динамических условий разломообразования в разнотипных природных регионах. Как следствие, задачей дальнейших исследований является тестирование тектонофизического подхода и геоэлектрической модели в различных структурно-тектонических и ландшафтно-климатических обстановках проведения малоглубинной электротомографии.

\section{6. БЛАГОДАРНОСТИ}

Авторы благодарны сотрудникам лаборатории тектонофизики Института земной коры СО РАН кандидатам наук А.В. Черемных и Ю.П. Бурзуновой, инженерам Р.M. Зарипову, А.К. Семинскому и A.C. Черемных за помощь в проведении полевых геофизических работ и обсуждение их результатов. Исследования проведены при частичной поддержке РФФИ (проект № 16-05-00154). 


\section{7. ЛИТЕРАTУРA / REFERENCES}

Al-Zubedi A.S., Thabit J.M., AL-Hameedawi M.M., 2015. Delineation of subsurface fractures density within and out of Abu-Jir Fault zone using 2D imaging resistivity technique, a case study from southwest of Karbala City, Central Iraq. Iraqi Journal of Science 56 (1B), 466-473.

Bense V.F., Gleeson T., Loveless S.E., Bour O., Scibek J., 2013. Fault zone hydrogeology. Earth-Science Reviews 127, 171-192. https://doi.org/10.1016/j.earscirev.2013.09.008.

Berg S.S., Skar T., 2005. Controls on damage zone asymmetry of a normal fault zone: outcrop analyses of a segment of the Moab fault, SE Utah. Journal of Structural Geology 27 (10), 1803-1822.

Bhat G.R., Balaji S., Bali B.S., Iqbal V., Hussain H., 2018. Paleoseismological investigations along Joggers Park Fault, Port Blair, South Andaman: Implications towards delineation of blind thrusting and related crustal deformation through ground penetrating radar (GPR) and electrical resistivity techniques (ERT and VES). Journal of the Geological Society of India 91 (1), 81-90. https://doi.org/10.1007/s12594-018-0823-z.

Bokun A.N., 1985. Development and character of fractures in the models of flexure-shape bending. In: I.V. Luchitsky, P.M. Bondarenko (Eds.), Experimental tectonics in theoretical and applied geology. Nauka, Moscow, p. 230-237 (in Russian) [Бокун A.H. Развитие и характер трещин в моделях флексурообразного изгиба // Экспериментальная тектоника в теоретической и прикладной геологии / Ред. И.В. Лучицкий, П.М. Бондаренко. М.: Наука, 1985. С. 230-237].

Burg J.P., 2018. Script to Tectonics. Lectures 650-3521-00L and 650-3521-00V. ETH Zurich.

Burzunova Yu.P., 2014. Joint systems in rocks of active tectonic regions: irregularity degree estimation. Bulletin of Irkutsk State Technical University (4), 45-49 (in Russian) [Бурзунова Ю.П. Трещинные сети в породах тектонически активных регионов: оценка степени хаотичности // Вестник Иркутского государственного технического университета. 2014. № 4. С. 45-49].

Caine J.S., Evans J.P., Forster C.B., 1996. Fault zone architecture and permeability structure. Geology 24 (11), 1025-1028. https://doi.org/10.1130/0091-7613(1996)024<1025:FZAAPS>2.3.CO;2.

Cheremnykh A.V., 2010. Internal structures of fault zones in the Priolkhonie and evolution of the state of stresses of the upper crust of the Baikal rift. Geodynamics \& Tectonophysics 1 (3), 273-284 (in Russian) [Черемных A.B. Внутренняя структура разломных зон Приольхонья и эволюция напряженного состояния верхней коры Байкальского рифта // Геодинамика и тектонофизика. 2010. Т. 1. № 3. C. 273-284]. https://doi.org/10.5800/GT2010-1-3-0021.

Chester F.M., Evans J.P., Biegel R.L., 1993. Internal structure and weakening mechanisms of the San Andreas fault. Journal of Geophysical Research: Solid Earth 98 (B1), 771-786. https://doi.org/10.1029/92JB01866.

Choi J.H., Edwards P., Ko K., Kim Y.S., 2016. Definition and classification of fault damage zones: A review and a new methodological approach. Earth-Science Reviews 152, 70-87. https://doi.org/10.1016/j.earscirev.2015.11.006.

Clausen J.A., Gabrielsen R.H., Johnsen E., Korstgård J.A., 2003. Fault architecture and clay smear distribution. Examples from field studies and drained ring-shear experiments. Norwegian Journal of Geology/Norsk Geologisk Forening 83 (2), 131-146.

Delvaux D., Moyes R., Stapel G., Melnikov A., Ermikov V., 1995. Palaeostress reconstructions and geodynamics of the Baikal region, Central Asia, Part I. Palaeozoic and Mesozoic pre-rift evolution. Tectonophysics 252 (1-4), 61-101. https://doi.org/10.1016/0040-1951(95)00090-9.

Delvaux D., Moyes R., Stapel G., Petit C., Levi K., Miroshnichenko A., Ruzhich V., San'kov V., 1997. Paleostress reconstructions and geodynamics of the Baikal region, Central Asia, Part 2. Cenozoic rifting. Tectonophysics 282 (1-4), 1-38. https://doi.org/10.1016/S0040-1951(97)00210-2.

Demanet D., Renardy F., Vanneste K., Jongmans D., Camelbeeck T., Meghraoui M., 2001. The use of geophysical prospecting for imaging active faults in the Roer Graben, Belgium. Geophysics 66 (1), 78-89. https://doi.org/10.1190/ 1.1444925 .

Dombrovskaya Zh.V., 1973. Paleogene Weathering Crust of Central Pribaikalie. Nauka, Moscow, 153 p. (in Russian) [Домбровская Ж.В. Палеогеновая кора выветривания Центрального Прибайкалья. М.: Наука, 1973. 153 с.].

Drahor M.G., Berge M.A., 2017. Integrated geophysical investigations in a fault zone located on southwestern part of İzmir city, Western Anatolia, Turkey. Journal of Applied Geophysics 136, 114-133. https://doi.org/10.1016/ j.jappgeo.2016.10.021.

Faulkner D.R., Jackson C.A.L., Lunn R.J., Schlische R.W., Shipton Z.K., Wibberley C.A.J., Withjack M.O., 2010. A review of recent developments concerning the structure, mechanics and fluid flow properties of fault zones. Journal of Structural Geology 32 (11), 1557-1575. https://doi.org/10.1016/j.jsg.2010.06.009.

Fazzito S.Y., Rapalini A.E., Cortés J.M., Terrizzano C.M., 2009. Characterization of Quaternary faults by electric resistivity tomography in the Andean Precordillera of Western Argentina. Journal of South American Earth Sciences 28 (3), 217-228. https://doi.org/10.1016/j.jsames.2009.06.001.

Fedorovsky V.S., 1997. Dome tectonics in the Caledonian collision system of Western Cisbaikalia. Geotectonics 31 (6), 483-497. 
Fischer T., Štěpančíková P., Karousová M., Tábořík P., Flechsig C., Gaballah M., 2012. Imaging the Mariánské Lázně Fault (Czech Republic) by 3-D ground-penetrating radar and electric resistivity tomography. Studia Geophysica et Geodaetica 56 (4), 1019-1036. https://doi.org/10.1007/s11200-012-0825-z.

Galli P.A.C., Giocoli A., Peronace E., Piscitelli S., Quadrio B., Bellanova J., 2014. Integrated near surface geophysics across the active Mount Marzano Fault System (southern Italy): seismogenic hints. International Journal of Earth Sciences 103 (1), 315-325. https://doi.org/10.1007/s00531-013-0944-y.

Grigoriev A.S., Volovich I.M., Mikhailova A.V., Rebetsky Yu.L., Shakhmuradova Z.E., 1987. Investigation of the stress state, kinematics and development of discontinuities of the sedimentary cover over the active faults of the basement (using a combination of mathematical and physical modeling in the conditions of plane deformation). In: Yu.D. Bulanzhe (Ed.), Stress and strain fields in the Earth crust. Nauka, Moscow, p. 5-31 (in Russian) [Григорьев А.C., Волович И.М., Михайлова А.В., Ребецкий Ю.Л., Шахмурадова З.Е. Исследование напряженного состояния, кинематики и развития нарушений сплошности осадочного чехла над активными разломами фундамента (при сочетании математического и физического моделирования в условиях плоской деформации) // Поля напряжений и деформаций в земной коре / Ред. Ю.Д. Буланже. М.: Наука, 1987. С. 5-31].

Jeanne P., Guglielmi Y., Cappa F., 2012. Multiscale seismic signature of a small fault zone in a carbonate reservoir: Relationships between VP imaging, fault zone architecture and cohesion. Tectonophysics 554-557, 185-201. https:// doi.org/10.1016/j.tecto.2012.05.012.

Jones G., Knipe R.J., 1996. Seismic attribute maps; application to structural interpretation and fault seal analysis in the North Sea basin. First Break 14 (12), 449-461. https://doi.org/10.3997/1365-2397.1996024.

Komolafe A.A., Kuria Z.N., Woldai T., Noomen M., Anifowose A.Y.B., 2012. Integrated remote sensing and geophysical investigations of the geodynamic activities at Lake Magadi, Southern Kenyan rift. International Journal of Geophysics 2012, Article ID 318301. https://doi.org/10.1155/2012/318301.

Kozhevnikov N.O., 2015. Regional structure of the Olkhon region according to the data of electromagnetic sounding and the electric-field method. Interexpo Geo-Siberia 2 (2), 107-112 (in Russian) [Кожевников Н.О. Региональная структура Приольхонья по данным электромагнитных зондирований и метода ЕП // Интерэкспо ГеоСибирь. 2015. Т. 2. №. 2. С. 107-112].

Kukley L.N., 1985. Precambrian of Western Pribaikalie. IPE RAS, Moscow, 189 p. (in Russian) [Куклей Л.Н. Докембрий Западного Прибайкалья. М.: ИФЗ РАН, 1985. 189 с.].

Levi K.G., Arzhannikova A.V., Buddo V.Yu., Kirillov P.G., Lukhnev A.V., Miroshnichenko A.I., Ruzhitch V.V., San'kov V.A., 1997. Recent geodynamics of the Baikal rift. Razvedka i okhrana nedr (1), 10-20 (in Russian) [Леви К.Г., Аржанникова А.В., Буддо В.Ю., Кириллов П.Г., Лухнев А.В., Мирошниченко А.И., Ружич В.В., Саньков В.А. Современная геодинамика Байкальского рифта // Разведка и охрана недр. 1997. № 1. С. 10-20].

Logachev N.A., 2003. History and geodynamics of the Baikal rift. Geologiya i Geofizika (Russian Geology and Geophysics) 44 (5), 391-406.

Loke M.H., 2010. Tutorial: RES2DINV ver. 3.59, Rapid 2-D Resistivity \& IP inversion using the least-squares method. Geotomo Software, Malaysia, $148 \mathrm{p}$.

Mats V.D., 1993. The structure and development of the Baikal rift depression. Earth-Science Reviews 34 (2), 81-118. https://doi.org/10.1016/0012-8252(93)90028-6.

Mats V.D., Ufimtsev G.F., Mandel'baum M.M., Alakshin A.M., Pospeev A.V., Shimaraev M.N., Khlystov O.M., 2001. The Baikal Basin in the Cenozoic: Structure and Geologic History. Siberian Branch of RAS Publishing House, Filial "Geo", Novosibirsk, 252 p. (in Russian) [Мац В.Д., Уфимцев Г.Ф., Мандельбаум М.М., Алакшин А.М., Поспеев А.В., Шимараев М.Н., Хлыстов О.М. Кайнозой Байкальской рифтовой впадины: строение и геологическая история. Новосибирск: Изд-во СО РАН, филиал «Гео», 2001. 252 с.].

Mitchell T.M., Faulkner D.R., 2009. The nature and origin of off-fault damage surrounding strike-slip fault zones with a wide range of displacements: A field study from the Atacama fault system, northern Chile. Journal of Structural Geology 31 (8), 802-816. https://doi.org/10.1016/j.jsg.2009.05.002.

Moisidi M., Vallianatos F., Soupios P., Kershaw S., 2012. Spatial spectral variations of microtremors and electrical resistivity tomography surveys for fault determination in southwestern Crete, Greece. Journal of Geophysics and Engineering 9 (3), 261-270. https://doi.org/10.1088/1742-2132/9/3/261.

Negri S., Leucci G., 2006. Geophysical investigation of the temple of Apollo (Hierapolis, Turkey). Journal of Archaeological Science 33 (11), 1505-1513. https://doi.org/10.1016/j.jas.2006.02.003.

Palacky G.J., 1989. Resistivity characteristics of geologic targets. In: M.N. Nabighian (Ed.), Electromagnetic methods in applied geophysics. Vol. 1. Theory. Society of Exploration Geophysicists, Tulsa, Oklahoma, p. 52-129. https:// doi.org/10.1190/1.9781560802631.ch3.

Patton T.L., Logan J.M., Friedman M., 1998. Experimentally generated normal faults in single-layer and multilayer limestone specimens at confining pressure. Tectonophysics 295 (1-2), 53-77. https://doi.org/10.1016/S00401951(98)00115-2.

Pavlov S.F. (Ed.), 1979. Ratio of Ancient and Cenozoic Structures in the Baikal Rift Zone. Nauka, Novosibirsk, 126 p. (in Russian) [Соотношение древней и кайнозойской структур в Байкальской рифтовой зоне / Ред. С.Ф. Павлов. Новосибирск: Наука, 1979. 126 с.]. 
Pedrera A., Marín-Lechado C., Stich D., Ruiz-Constán A., Galindo-Zaldívar J., Rey-Moral C., de Lis Mancilla F., 2012. Nucleation, linkage and active propagation of a segmented Quaternary normal-dextral fault: the Loma del Viento fault (Campo de Dalías, Eastern Betic Cordillera, SE Spain). Tectonophysics 522-523, 208-217. https://doi.org/ 10.1016/j.tecto.2011.12.001.

Pleshanov S.P., Romazina A.A., 1981. Some problems of kinematics of faulting in the central Baikal rift. In: N.A. Logachev, S.I. Sherman (Eds.), Problems of fault tectonics. Nauka, Novosibirsk, p. 129-141 (in Russian) [Плешанов С.П., Ромазина А.A. Некоторые вопросы кинематики развития разломов центральной части Байкальского рифта // Проблемы разломной тектоники / Ред. Н.А. Логачев, С.И. Шерман. Новосибирск: Наука, 1981. C. 129-141].

Putiška R., Dostál I., Mojzeš A., Gajdoš V., Rozimant K., Vojtko R., 2012. The resistivity image of the Muráň fault zone (Central Western Carpathians) obtained by electrical resistivity tomography. Geologica Carpathica 63 (3), 233-239. https://doi.org/10.2478/v10096-012-0017-3.

Schueller S., Braathen A., Fossen H., Tveranger J., 2013. Spatial distribution of deformation bands in damage zones of extensional faults in porous sandstones: Statistical analysis of field data. Journal of Structural Geology 52, 148-162. https://doi.org/10.1016/j.jsg.2013.03.013.

Schütze C., Vienken T., Werban U., Dietrich P., Finizola A., Leven C., 2012. Joint application of geophysical methods and Direct Push-soil gas surveys for the improved delineation of buried fault zones. Journal of Applied Geophysics 82, 129-136. https://doi.org/10.1016/j.jappgeo.2012.03.002.

Seminsky K.Zh., 2014. Specialized mapping of crustal fault zones. Part 1: Basic theoretical concepts and principles. Geodynamics \& Tectonophysics 5 (2), 445-467 (in Russian) [Семинский К.Ж. Спецкартирование разломных зон земной коры. Статья 1: Теоретические основы и принципы // Геодинамика и тектонофизика. 2014. Т. 5. № 2. C. 445-467]. https://doi.org/10.5800/GT-2014-5-2-0136.

Seminsky K.Zh., 2015. Specialized mapping of crustal fault zones. Part 2: Main stages and prospects. Geodynamics \& Tectonophysics 6 (1), 1-43 (in Russian) [Семинский К.Ж. Спецкартирование разломных зон земной коры. Статья 2: Основные этапы и перспективы // Геодинамика и тектонофизика. 2015. Т. 6. № 1. С. 1-43]. https:// doi.org/10.5800/GT-2015-6-1-0170.

Seminsky K.Zh., Bobrov A.A., 2012. Spatial and temporal variations of soil-radon activity in fault zones of the Pribaikalie (East Siberia, Russia). In: Z. Li, C. Feng (Eds.), Handbook of radon: properties, applications and health. Chapter 1. Nova Science Publishers, Inc., New York, 1-36.

Seminsky K.Zh., Bobrov A.A., Demberel S., 2014. Variations in radon activity in the crustal fault zones: Spatial characteristics. Izvestiya, Physics of the Solid Earth 50 (6), 795-813. https://doi.org/10.1134/S1069351314060081.

Seminsky K.Zh., Demberel S., 2013. The first estimations of soil-radon activity near faults in Central Mongolia. Radiation Measurements 49, 19-34. https://doi.org/10.1016/j.radmeas.2012.12.013.

Seminsky K.Zh., Kozhevnikov N.O., Cheremnykh A.V., Bobrov A.A., Olenchenko V.V., Avgulevich D.L., 2008. Structure of the fault zones in Priol'khonie (Baikal rift) as derived from tectonophysical and geophysical surveys. Proceedings of the Siberian Department of the Section of Earth Sciences of the Russian Academy of Natural Sciences. Geology, Exploration and Development of Mineral Deposits (7), 111-124 (in Russian) [Семинский К.Ж., Кожевников Н.О., Черемных А.В., Бобров А.А., Оленченко В.В., Авгулевич Д.Л. Структура разломных зон Приольхонья (Байкальский рифт) по данным полевой тектонофизики и геофизики // Известия Сибирского отделения Секции наук о Земле Российской академии естественных наук. Геология, разведка и разработка месторождений полезных ископаемых. 2008. № 7 (33). С. 111-124].

Seminsky K.Zh., Kozhevnikov N.O., Cheremnykh A.V., Pospeeva E.V., Bobrov A.A., Olenchenko V.V., Tugarina M.A., Potapov V.V., Zaripov R.M., Cheremnykh A.S., 2013. Interblock zones in the crust of the southern regions of East Siberia: tectonophysical interpretation of geological and geophysical data. Geodynamics \& Tectonophysics 4 (3), 203-278 (in Russian) [Семинский К.Ж., Кожевников Н.О., Черемных А.В., Поспеева Е.В., Бобров А.А., Оленченко В.В., Тугарина М.А., Поmanов B.B., Зарипов P.M., Черемных A.C. Межблоковые зоны в земной коре юга Восточной Сибири: тектонофизическая интерпретация геолого-геофизических данных // Геодинамика и тектонофизика. 2013. Т. 4. № 3. C. 203-278]. https://doi.org/10.5800/GT-2013-4-3-0099.

Seminsky K.Zh., Zaripov R.M., Olenchenko V.V., 2016. Interpretation of shallow electrical resistivity images of faults: tectonophysical approach. Russian Geology and Geophysics 57 (9), 1349-1358. https://doi.org/10.1016/j.rgg. 2016.08.020.

Sherman S.I., 1977. Physical Regularities of Faulting in the Earth's Crust. Siberian Branch, Nauka, Novosibirsk, 102 p. (in Russian) [Шерман С.И. Физические закономерности развития разломов земной коры. Новосибирск: Наука. СО, 1977. 102 с.].

Sherman S.I., Seminsky K.Zh., Bornyakov S.A., Adamovich A.N., Buddo V.Yu., 1994. Faulting in the Lithosphere. Compresson Zones. Nauka, Siberian Branch, Novosibirsk, 263 p. (in Russian) [Шерман С.И., Семинский К.Ж., Борняков С.А., Адамович А.Н., Буддо В.Ю. Разломообразование в литосфере. Зоны сжатия. Новосибирск: Наука. СО, 1994. 263 c.].

Sherman S.I., Seminsky K.Zh., Bornyakov S.A., Adamovich A.N., Lobatskaya R.M., Lysak S.V., Levi K.G., 1992. Faulting in the Lithosphere. Extension Zones. Nauka, Novosibirsk, 262 p. (in Russian) [Шерман С.И., Семинский К.Ж., Борняков С.А., Адамович А.Н., Лобацкая Р.М., Лысак С.В., Леви К.Г. Разломообразование в литосфере. Зоны растяжения. Новосибирск: Наука, 1992. 262 с.]. 
Sklyarov E.V. (Ed.), 2005. Structural and Tectonic Correlation Across the Central Asia Orogenic Collage: North-Eastern Segment. Guidebook and Abstract Volume of the Siberian Workshop IGCP-480. IEC SB RAS, Irkutsk, $291 \mathrm{p}$.

Štěpančíková P., Hók J., Nývlt D., Dohnal J., Sýkorová I., Stemberk J., 2010. Active tectonics research using trenching technique on the south-eastern section of the Sudetic Marginal Fault (NE Bohemian Massif, central Europe). Tectonophysics 485 (1-4), 269-282. https://doi.org/10.1016/j.tecto.2010.01.004.

Thinova L., Fronka A., Rovenska K., 2011. A pilot study of the dependence of radon concentration on the tectonic structures, using simple geophysical methods. Radiation Protection Dosimetry 145 (2-3), 159-165. https://doi.org/ $10.1093 / \mathrm{rpd} / \mathrm{ncr} 070$.

Vanneste K., Verbeeck K., Petermans T., 2008. Pseudo-3D imaging of a low-slip-rate, active normal fault using shallow geophysical methods: The Geleen fault in the Belgian Maas River valley. Geophysics 73 (1), B1-B9. https://doi.org/ 10.1190/1.2816428.

Zaripov R.M., 2013. Features of using electrical resistivity tomography in the study of fault zones in the Olkhon region (Western Baikal region). In: Trofimuk Seminar - 2013. IPGG, Novosibirsk, p. 271-274 (in Russian) [Зарипов P.M. Особенности применения электротомографии при исследовании разломных зон Приольхонья (Западное Прибайкалье) // Трофимуковские чтения - 2013. Новосибирск: ИНГГ, 2013. С. 271-274].

Zarroca M., Linares R., Bach J., Roqué C., Moreno V., Font L., Baixeras C., 2012. Integrated geophysics and soil gas profiles as a tool to characterize active faults: the Amer fault example (Pyrenees, NE Spain). Environmental Earth Sciences 67 (3), 889-910. https://doi.org/10.1007/s12665-012-1537-y.

Zhu T., Zhou J., Wang H., 2017. Localization and characterization of the Zhangdian-Renhe fault zone in Zibo city, Shandong province, China, using electrical resistivity tomography (ERT). Journal of Applied Geophysics 136, 343-352. https://doi.org/10.1016/j.jappgeo.2016.11.016.

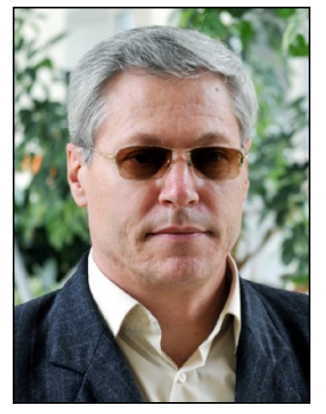

Константин Жанович Семинский, докт. геол.-мин. наук, заместитель директора Институт земной коры СО РАН

664033, Иркутск, ул. Лермонтова, 128, Россия

凶e-mail: seminsky@crust.irk.ru

ORCID ID https://orcid.org/0000-0001-7607-0417

Konstantin Zh. Seminsky, Doctor of Geology and Mineralogy, Deputy Director Institute of the Earth's Crust, Siberian Branch of RAS 128 Lermontov street, Irkutsk 664033, Russia

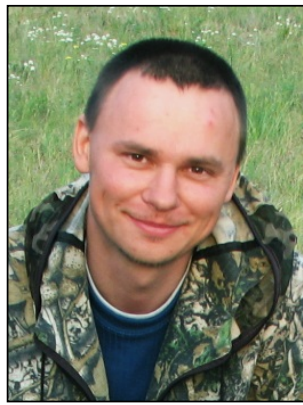

Александр Анатольевич Бобров, канд. геол.-мин. наук, н.с.

Институт земной коры СО РАН

664033, Иркутск, ул. Лермонтова, 128, Россия

e-mail: alexbob@crust.irk.ru

ORCID ID https://orcid.org/0000-0002-4405-6132

Alexander A. Bobrov, Candidate of Geology and Mineralogy, Researcher Institute of the Earth's Crust, Siberian Branch of RAS

128 Lermontov street, Irkutsk 664033, Russia 